\title{
Folding of the hammerhead ribozyme: Pyrrolo-cytosine fluorescence separates core folding from global folding and reveals a $\mathrm{pH}$-dependent conformational change
}

\author{
IWONA A. BUSKIEWICZ ${ }^{1}$ and JOHN M. BURKE \\ Department of Microbiology and Molecular Genetics, University of Vermont, Burlington, Vermont 05405, USA
}

\begin{abstract}
The catalytic activity of the hammerhead ribozyme is limited by its ability to fold into the native tertiary structure. Analysis of folding has been hampered by a lack of assays that can independently monitor the environment of nucleobases throughout the ribozyme-substrate complex in real time. Here, we report the development and application of a new folding assay in which we use pyrrolo-cytosine (pyC) fluorescence to (1) probe active-site formation, (2) examine the ability of peripheral ribozyme domains to support native folding, (3) identify a pH-dependent conformational change within the ribozyme, and (4) explore its influence on the equilibrium between the folded and unfolded core of the hammerhead ribozyme. We conclude that the natural ribozyme folds in two distinct noncooperative steps and the $\mathrm{pH}$-dependent correlation between core folding and activity is linked to formation of the G8-C3 base pair.
\end{abstract}

Keywords: hammerhead ribozyme; catalytic RNA; RNA folding; pyrrolo-cytosine

\section{INTRODUCTION}

The hammerhead ribozyme is a small, self-cleaving RNA motif, first discovered in viroids and satellite RNAs of plant viruses (Prody et al. 1986; Forster and Symons 1987). It catalyzes a specific phosphodiester bond isomerization reaction in the course of the rolling-circle replication of these respective RNA species and has been implicated in RNA processing reactions in vertebrate satellite RNA and mRNA (Chartrand et al. 1995; Ferbeyre et al. 1998). The minimal hammerhead may be the simplest self-processing RNA and consists of a conserved core of about 15 mostly invariant core residues at a three-helix junction (Ruffner et al. 1990). However, optimal activity requires the presence of peripheral sequences that interact via tertiary contacts (De la Pena et al. 2003; Khvorova et al. 2003). In the crystal structures of the Schistosoma mansoni hammerhead ribozyme, an interaction between a peripheral Stem II loop and a Stem I bulge is proposed to lead to structural organization of the catalytic core (Martick and Scott 2006). Additionally, structures obtained in the presence of manganese ions, together with molecular

\footnotetext{
${ }^{1}$ Corresponding author.

E-mail ibuskiew@uvm.edu.

Article published online ahead of print. Article and publication date are at http://www.rnajournal.org/cgi/doi/10.1261/rna.030999.111.
}

dynamics simulations, have provided insights into the location and potential functions of divalent metal ions and solvent in the hammerhead ribozyme catalysis (Lee et al. 2008; Martick et al. 2008).

Fluorescence resonance energy transfer (FRET) (Penedo et al. 2004) and electron paramagnetic resonance (EPR) (Kim et al. 2005) studies have shown that global folding occurs at much lower magnesium ion $\left(\mathrm{Mg}^{2+}\right)$ concentrations in the extended construct compared with the minimal ribozyme. Peripheral loops act as auxiliary elements that support ribozyme function, presumably by promoting global folding under physiological conditions, as indicated by an apparent single-step folding pathway (Penedo et al. 2004). The minimal ribozyme folds in two distinct steps, as demonstrated by various studies (Hammann and Lilley 2002; Hampel and Burke 2003). Recent work performed with time-resolved FRET (tr-FRET) and single-molecule FRET (sm-FRET) techniques to monitor the global structure and dynamics of three hammerheads based on the Avocado Sunblotch Viroid sequence invoke a linkage between RNA structural dynamics and function. This work suggests that loop-loop interactions in extended hammerhead ribozymes and $\mathrm{Mg}^{2+}$ ions that bind to minimal ribozymes may generally allow more frequent access to a catalytically relevant conformation(s), rather than simply locking the ribozyme into a single active state (McDowell et al. 2010). Strikingly, both minimal and 
natural hammerhead ribozyme catalysis requires significantly higher $\mathrm{Mg}^{2+}$ concentrations than those required for tertiary folding (Rueda et al. 2003). The identity of the divalent metal ion has little effect on global folding, whereas it has a very large effect on the cleavage kinetics (Roychowdhury-Saha and Burke 2006; Boots et al. 2008).

Folding and catalytic activity are related at several levels in these RNA species. To date, elucidating of the folding pathways has been hampered by the lack of assays that can independently monitor the environment of nucleobases throughout the ribozyme-substrate complex in real time without structural ambiguity. Here, we describe a fast kinetic folding analysis approach using the highly sensitive fluorescent cytosine analog pyrrolo-cytosine (pyC) (Berry et al. 2004). pyC forms a Watson-Crick-like base pair with guanosine and was shown to maintain all structural and thermodynamic features of a standard guanosine-cytosine base pair (Dash et al. 2004; Thompson and Miyake 2005; Tinsley and Walter 2006; Zhang and Wadkins 2009). Its incorporation at multiple positions in the extended hammerhead ribozyme was previously shown not to interfere with the function of the ribozyme (Lambert et al. 2006). The combination of mutational substitution, kinetics, and $\mathrm{pyC}$ folding analysis has allowed us to experimentally access multiple stages of hammerhead ribozyme folding, to determine the $\mathrm{pH}$ dependence of folding, and to establish how G8-C3/C17 equilibrium may be functionally linked to the core folding event.

\section{RESULTS}

\section{Distinct folding of catalytic core and auxiliary structural elements}

Using a native hammerhead ribozyme motif derived from S. mansoni sequences (Fig. 1A), folding was analyzed by stopped-flow fluorescence spectroscopy. Ribozyme-substrate complexes in which the fluorophore pyC (Fig. 1B) was introduced at two positions within the core ( $\mathrm{pyC} 3$ and pyC7, respectively), one at the base of Stem I (pyC1.1) and one in a peripheral loop (pyC1.9) (Fig. 1A), were examined. These substitutions had no significant effect on the catalytic activity of the complex at any $\mathrm{pH}$ studied or variant used (Supplemental Fig. S1A-D). The secondary structure formation of the ground-state ribozyme-substrate complex in the presence and absence of pyC was justified by use of hydroxyl footprinting mapping as previously established and described (Hampel and Burke 2003; Lambert et al. 2006). Furthermore, mobility-shift gel assays were conducted to test the homogeneity of ribozyme-substrate complexes carrying the fluorophore at different positions, as well as for complexes carrying point mutations. The yield and the stability of the binary complex were monitored in the absence and presence of $\mathrm{Mg}^{2+}$ and at all studied pHs (Supplemental Fig. S4).

Upon induction of folding by mixing with $\mathrm{Mg}^{2+}$ (final concentrations $0.05-100 \mathrm{mM}$ ), significant fluorescence changes
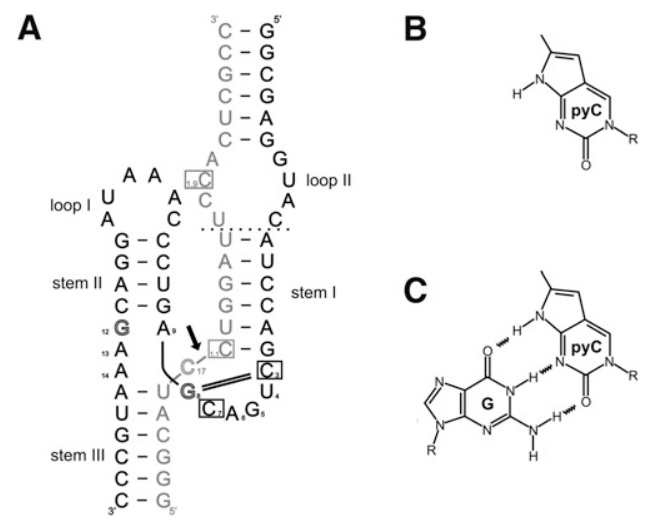

FIGURE 1. (A) Secondary structure of the Schistosoma mansoni hammerhead ribozyme construct used in this study. This representation emphasizes the global geometry as seen in the first crystal structure of the S. mansoni ribozyme (Martick and Scott 2006). Enzyme strand (black); the substrate (gray); and positions of nucleotides replaced with the fluorescent analog (boxed). Outlined letters (C17, G8, and G12) indicate core nucleotides essential for catalysis, and the cleavage site is marked with a black arrow; the canonical 8-3 Watson-Crick base pair is shown as a black double line. Thick black and gray lines indicate backbone continuity, where the sequence has been separated for diagrammatic clarity. Base numbering is according to Hertel (Hertel et al. 1992). The dotted line in the region of Loop 1 shows the truncation position of the substrate and ribozyme strands to form the minimal form of the ribozyme lacking the tertiary interaction. (B) Structure of pyrrolo-cytosine (pyC) and (C) pyrrolo-cytosine-guanosine base pair (pyC-G).

were observed in all cases. For pyC3, pyC1.1, and pyC1.9, we observed a decrease of fluorescence (pyC3: $F / F_{0}=0.92$; pyC1.1: $F / F_{0}=0.82$; pyC1.9: $F / F_{0}=0.58$ ), and for pyC7, we observed an increase in fluorescence of $F / F_{0}$ equal to 1.43 (Fig. 2A).

The strong fluorescence decrease for pyC1.9, located in the loop region, indicates that in the absence of $\mathrm{Mg}^{2+}$, the loops must be in a different arrangement from in the fully folded state. The conformational change leading to the loop-loop interaction leads to either exposure of the pyC residue to the solvent or brings the $\mathrm{C} 1.9$ close to guanosine residues, which were shown to quench pyC (Hardman et al. 2008). Indeed, in the crystal structure of the native hammerhead (Supplemental Fig. S2A), C1.9 is located in the groove open to solvent and is forming close interactions with guanosine B1 (Martick and Scott 2006). The photo-induced electron transfer from proximal guanosines to pyC appears to induce much stronger quenching than exposure to solvent and reactive oxygen species (to be published elsewhere). Similar effects were observed for 2-aminopurine or fluorescein incorporated into RNA or DNA (Walter and Burke 1997; Kelley and Barton 1999).

The fluorescence decrease for the core residue pyC 3 and pyC1.1, as well as the fluorescence increase for position pyC7, agrees well with the residues transferring from ground to active conformation as represented by the crystal structures of the minimal and natural ribozymes. The structure of the minimal ribozyme is generally assumed to be close to the 
A

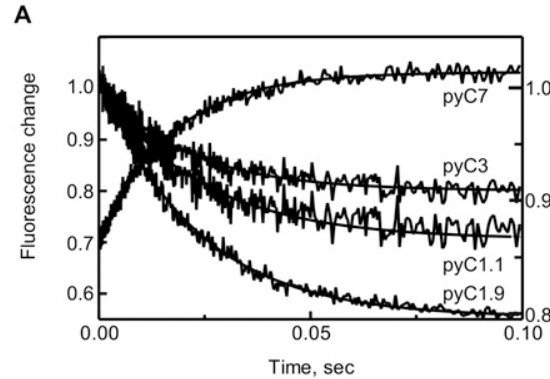

C

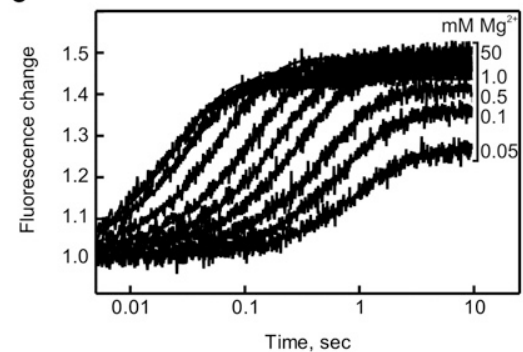

B

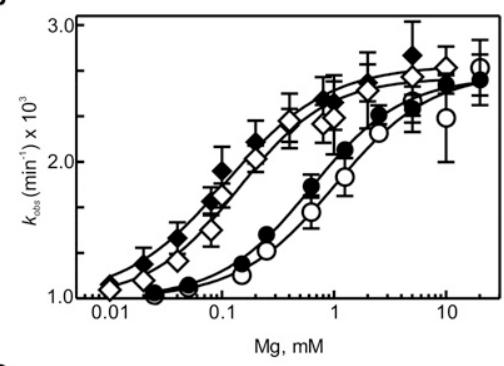

D

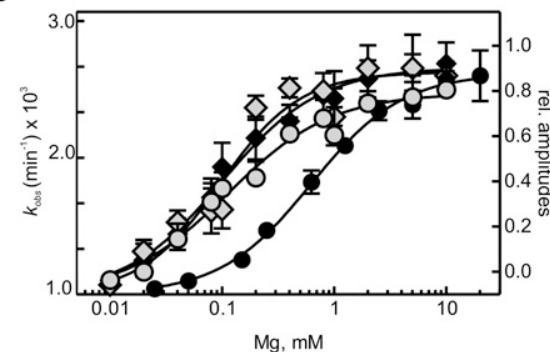

FIGURE 2. Folding of $S$. mansoni hammerhead ribozyme as observed by pyC fluorescence changes in stopped-flow fluorimeter. (A) Time courses of hammerhead ribozyme-substrate (noncleavable) complex folding upon exposure to $10 \mathrm{mM} \mathrm{Mg}^{2+}$, in the presence of $50 \mathrm{mM}$ Tris- $\mathrm{HCl}$ and $100 \mathrm{mM} \mathrm{NaCl}(\mathrm{pH} 7.0)$ at $25^{\circ} \mathrm{C}$, as reported at positions in the Loop II (pyCl.9), Stem I (pyC1.1), and core region (pyC3 and pyC7). The displayed curves are averages of at least four measurements. The smooth lines represent the fit (see Materials and Methods). $(B)$ $k_{\text {obs }}$ (per minute) for folding plotted as a function of $\mathrm{Mg}^{2+}$ concentration. The data have been fitted to a two-state binding model yielding a Hill coefficient equal $\sim 1$ for all analyzed variants and an apparent dissociation constant $\left[\mathrm{Mg}^{2+}\right]_{1 / 2}: 0.12( \pm 0.01) \mathrm{mM}$ for pyCl.9 (black diamonds); 0.14 ( \pm 0.03 ) $\mathrm{mM}$ for pyC1.1 (open diamonds); $0.8( \pm 0.2) \mathrm{mM}$ for pyC3 (open circles); and $1.0( \pm 0.03) \mathrm{mM}$ for pyC7 (black circles). (C) An example of time courses of folding monitored in the core of the ribozyme at position pyC7 with increasing $\mathrm{Mg}^{2+}$ concentration. Please note earlier amplitude than observed rate constant saturation with increasing $\mathrm{Mg}^{2+}$ concentration. (D) Comparison of $\mathrm{Mg}^{2+}$ dependence of the apparent $k_{\mathrm{obs}}$ for pyC1.9 and pyC7 (black diamonds and circles) with $\mathrm{Mg}^{2+}$ dependence of their relative fluorescence amplitudes (gray diamonds and circles, respectively). (Left $y$-axis) $k_{\mathrm{obs}}$; (right $y$-axis) normalized relative amplitudes. The fluorescence amplitudes were normalized so that the maximal fluorescence amplitude observed in each experiment was valued at 1 . The apparent dissociation constant established from changing fluorescence amplitudes was $\left[\mathrm{Mg}^{2+}\right]_{1 / 2}: 0.09$ $( \pm 0.01) \mathrm{mM}$ for pyC1.9 (gray diamonds) and $0.11( \pm 0.03) \mathrm{mM}$ for pyC7 (gray circles).

ground state (Scott et al. 1996), and the S. mansoni ribozyme is assumed to be close to the active state (Martick and Scott 2006). In the ground state, C3 forms one hydrogen bond with $\mathrm{C} 17$, which is stabilized by stacking interactions, while in the active state, C3 forms a Watson-Crick base pair with G8. Since it has previously been shown that base-pairing of pyC with guanosine strongly lowers its quantum yield (Tinsley and Walter 2006), the observed decrease indicates a transition from ground to active state. For the C1.1, the base-pairing with G2.1 occurs in both ground and active states; therefore, the expected overall amplitude of signal change is small and depends only on the transition between stacking interactions with $\mathrm{C} 3$ in the ground state to the stacking interaction with the G8-C3 base pair in the active state. Congruently, the ground-state C7 is engaged in multiple interactions and strong base-stacking with G8 inside the ground-state core of the hammerhead ribozyme, whereas in the active state, C7 makes only a loose stacking interaction with C3 and is primarily exposed to the solvent. Hence, as anticipated for the ground-to-active-state transition, pyC7 responds with a strong fluorescence increase.

At moderate $\mathrm{Mg}^{2+}$ concentrations $(<20 \mathrm{mM})$, time courses of folding were accurately fit to a single-exponential rate equation with a maximal observed rate of $k_{\text {obs }}=2.7 \times 10^{3} \mathrm{~min}^{-1}$ at pH 7.0 (Fig. 2A). At higher $\mathrm{Mg}^{2+}$ concentrations $(>20 \mathrm{mM}$ ), the folding appeared to be biphasic, and only the faster, dominant apparent rate of folding was taken into consideration.

When fluorophores in one of the peripheral loops (pyC1.9) and at the junction of Stem I and the core (pyC1.1) were monitored, folding was well described by a two-state model induced by noncooperative $\mathrm{Mg}^{2+}$ binding with a Hill coefficient of $\sim 1$ and an apparent dissociation constant of $\left[\mathrm{Mg}^{2+}\right]_{1 / 2}=$ $0.12( \pm 0.01) \mathrm{mM}$ and $0.14( \pm 0.03)$ $\mathrm{mM}$ for pyC1.9 and pyC1.1, respectively. The maximum velocity at saturated $\mathrm{Mg}^{2+}$ concentrations reached $k_{\text {obs }}=$ $2.9 \times 10^{3} \mathrm{~min}^{-1}$ (Fig. 2B). In contrast, analysis of complexes with fluorophores within the core (pyC3 and pyC7) showed an order-of-magnitude-higher concentration of $\mathrm{Mg}^{2+}\left(\left[\mathrm{Mg}^{2+}\right]_{1 / 2}=1.0[ \pm 0.1\right.$ $\mathrm{mM}])$ to be required for the reaction to reach saturation and the same maximum velocity of $k_{\mathrm{obs}}=2.7 \times 10^{3} \mathrm{~min}^{-1}$ (Fig. 2B). Together, these observations suggest that the stem regions closed by peripheral loops and the core fold independently of one another, reaching the same velocity only at saturating magnesium ion concentrations. Equivalent velocities of global versus core folding at saturated $\mathrm{Mg}^{2+}$ concentrations indicate that overall global folding, if inhibited, might become the rate-limiting step.

The equilibrium $\mathrm{Mg}^{2+}$-induced folding of the ribozymesubstrate complex was analyzed not only by the dependence of the observed rate constants on $\mathrm{Mg}^{2+}$ concentration, but also by the dependence of the relative amplitudes of the fluorescence change on the concentration of $\mathrm{Mg}^{2+}$. The fluorescence amplitude and associated kinetic rate changes with $\mathrm{Mg}^{2+}$ concentration for Stem I (pyC1.1) and Loop II (pyC1.9) showed an exact correlation (Fig. 2D). Again, there was no apparent cooperativity in binding, and fitting yielded a $\left[\mathrm{Mg}^{2+}\right]_{1 / 2}=0.08( \pm 0.01) \mathrm{mM}$, suggesting a two-state global folding model for the hammerhead ribozyme. Interestingly, the fluorescence amplitude changes as a function of $\mathrm{Mg}^{2+}$ concentration for core position pyC3 (data not 
shown) and pyC7 (Fig. 2C,D) did not correlate with $\mathrm{Mg}^{2+}$ dependent changes of the related rate constants of folding. The increase in the amplitude of fluorescence change reached saturation at $\sim 1 \mathrm{mM} \mathrm{Mg}{ }^{2+}$; however, the rate of the fluorescence change kept increasing and saturated first at $\sim 10 \mathrm{mM} \mathrm{Mg}^{2+}$ (Fig. 2C,D). The dependence of fluorescence amplitude versus $\mathrm{Mg}^{2+}$ concentration for pyC3 and pyC7 was one order of magnitude lower $\left(\left[\mathrm{Mg}^{2+}\right]_{1 / 2}=0.12 \mathrm{mM}\right.$ $[ \pm 0.03])$ than that observed for their relative rates of folding and similar to that acquired for pyC1.1 and pyC1.9, assigned as global folding. This suggests that the presence of the looploop interaction does not influence core folding, but rather increases the fraction of the molecules able to fold the core into a transiently kinetic intermediate.

\section{pH-dependent conformational change}

The cleavage activity of the naturally occurring hammerhead ribozyme shows a log-linear $\mathrm{pH}$ dependence in the presence of $10 \mathrm{mM} \mathrm{Mg}^{2+}$ (Canny et al. 2004). A similar $\mathrm{pH}$ dependence has been previously observed for the minimal hammerhead (Clouet-D’Orval and Uhlenbeck 1996). However, in the presence of submillimolar concentrations of $\mathrm{Mg}^{2+}$, cleavage rates deviate from log-linear above $\mathrm{pH} 7.5$, suggesting a $\mathrm{pH}$-dependent conformational change, resulting in less efficient cleavage at high pH (Canny et al. 2004). To test this possibility, we measured the $\mathrm{pH}$ dependence of folding using hammerheads with pyC at positions in both the core and auxiliary elements. Fluorescence of pyC was previously shown to be insensitive to $\mathrm{pH}$ over the broad range used, pH 5.0-9.0 (Tinsley and Walter 2006). Examination of complexes with fluorophores in the peripheral loop (pyC1.9) and Stem I (pyC1.1) showed no significant change in folding rate as a function of $\mathrm{pH}$ (Fig. 3). In contrast, at the same $\mathrm{Mg}^{2+}$ concentration of $10 \mathrm{mM}$, complexes with fluorophores in the catalytic core (pyC3 and pyC7) showed a bell-shaped curve, with a 10 -fold increase in the folding rate from $\mathrm{pH} 5.5$ to 7.0 , followed by a sharp decrease in $k_{\text {obs }}$ between $\mathrm{pH} 7.0$ and 8.5 (Fig. 3). The rates of core folding at higher $\mathrm{pH}$ approached the rates of cleavage, indicating that core folding might become the rate-limiting step under these conditions. Fitting the data in Figure 3 to the HendersonHasselbalch equation yielded two apparent $\mathrm{pK}_{\mathrm{a}}$ values of 6.3 $( \pm 0.2)$ and $7.4( \pm 0.1)$, consistent with a model in which two protonation-deprotonation events take place within or adjacent to the active site. Furthermore, they suggest that the two $\mathrm{pK}_{\mathrm{a}}$ values observed in activity-based studies (Han and Burke 2005) may, at least in part, coincide with activesite conformational changes.

\section{pH-dependent conformational change-mutational analysis}

The $\mathrm{pH}$-induced folding changes at positions $\mathrm{C} 7$ and $\mathrm{C} 3$ are expected to be dependent on the secondary and tertiary

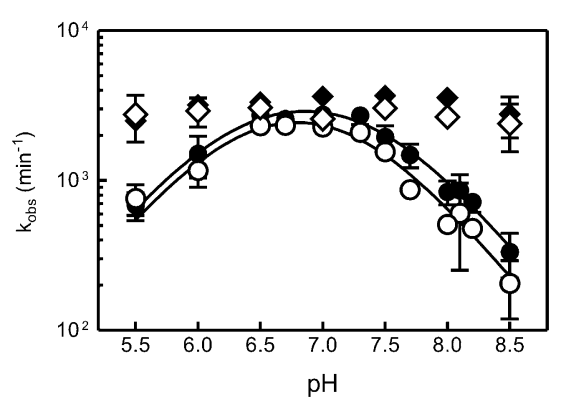

FIGURE 3. $\mathrm{pH}$ dependence of fluorescence-detected folding of the S. mansoni hammerhead ribozyme. The folding experiments at different $\mathrm{pH}$ values were performed in a stopped-flow fluorimeter by addition of $\mathrm{Mg}^{2+}(10 \mathrm{mM})$ to a pre-annealed complex of ribozyme and noncleavable substrate $(1 \mu \mathrm{M})$. The folding reactions were carried out at $25^{\circ} \mathrm{C}$ in the presence of $100 \mathrm{mM} \mathrm{NaCl}$ and $50 \mathrm{mM}$ MES (pH 5-6), MOPS (pH 6.5-7.5), HEPES (pH 7.0-8.0), TRIS (pH 7.5-8.5), TAPS ( $\mathrm{pH}$ 8.2-8.9), and CHES ( $\mathrm{pH} 8.5-9.0$ ). The folding traces were fitted as described in Materials and Methods. Extracted, log apparent rate constants $k_{\text {obs }}$ (per minute) were plotted as a function of $\mathrm{pH}$. The differences in the apparent rate of folding for loop pyC1.9 (black diamonds) and Stem I pyC1.1 (open diamonds) at different $\mathrm{pH}$ values did not exceed $10 \%$. The apparent rate of folding for core residues pyC7 (black circles) and pyC3 (open circles) shows at least a one order of magnitude lower rate of folding at high and low $\mathrm{pHs}$ as compared with $\mathrm{pH}$ 7.0. The apparent bell-shaped curve could be fitted to a Henderson-Hasselbalch-type equation (see Materials and Methods) yielding two apparent $\mathrm{pK}_{\mathrm{a}}$ values of $6.3( \pm 0.2)$ and $7.4( \pm 0.1)$.

structure of the core. Comparison of the ground-state and the active-state hammerhead crystal structures indicates that both residues change their position during the conformational transition and in the active state both stack beneath each other (Scott et al. 1996; Martick and Scott 2006). Hence, it is reasonable to predict that fluorescence changes of both pyC7 and pyC3 might monitor the same $\mathrm{pH}$-dependent folding event within the core, leading to the active-site formation. The equilibrium of the transition between both states of hammerhead folding was shown to be affected by G8-C3 base-pair formation (Przybilski and Hammann 2007a,b; Nelson and Uhlenbeck 2008). Since our earlier mutational analysis of G8 demonstrated effects both on cleavage activity and the $\mathrm{pH}$ profile of the reaction (Han and Burke 2005), we substituted the G8-C3 base pair with $\mathrm{pK}_{\mathrm{a}}$-altering nucleobase analogs and examined simultaneously the $\mathrm{pH}$ dependence of core folding and cleavage activity.

Substitution of G8 with inosine (I8) (Fig. 4A) would be expected to result in a base pair with $\mathrm{C} 3$ in Watson-Crick geometry, but with only two hydrogen bonds. As shown in Figure $4 \mathrm{~B}$, the $\mathrm{pH}$-dependent folding of the I8-C3 core appears quite similar to that of G8-C3; however, at higher $\mathrm{pH}$ values, the maximum velocity of folding is slower, and the decrease with $\mathrm{pH}$ is steeper than for G8-C3 (Table 3, below). The rate of cleavage for both G8-C3 and I8-C3 increases with $\mathrm{pH}$ in a log-linear manner and approaches 214 $\min ^{-1}$ at $\mathrm{pH} 8.5$ for G8-C3, while I8-C3 levels off at $\mathrm{pH} 7.5-$ 8.0 with a maximum velocity of only $\sim 50 \mathrm{~min}^{-1}$ (Fig. 4C; 

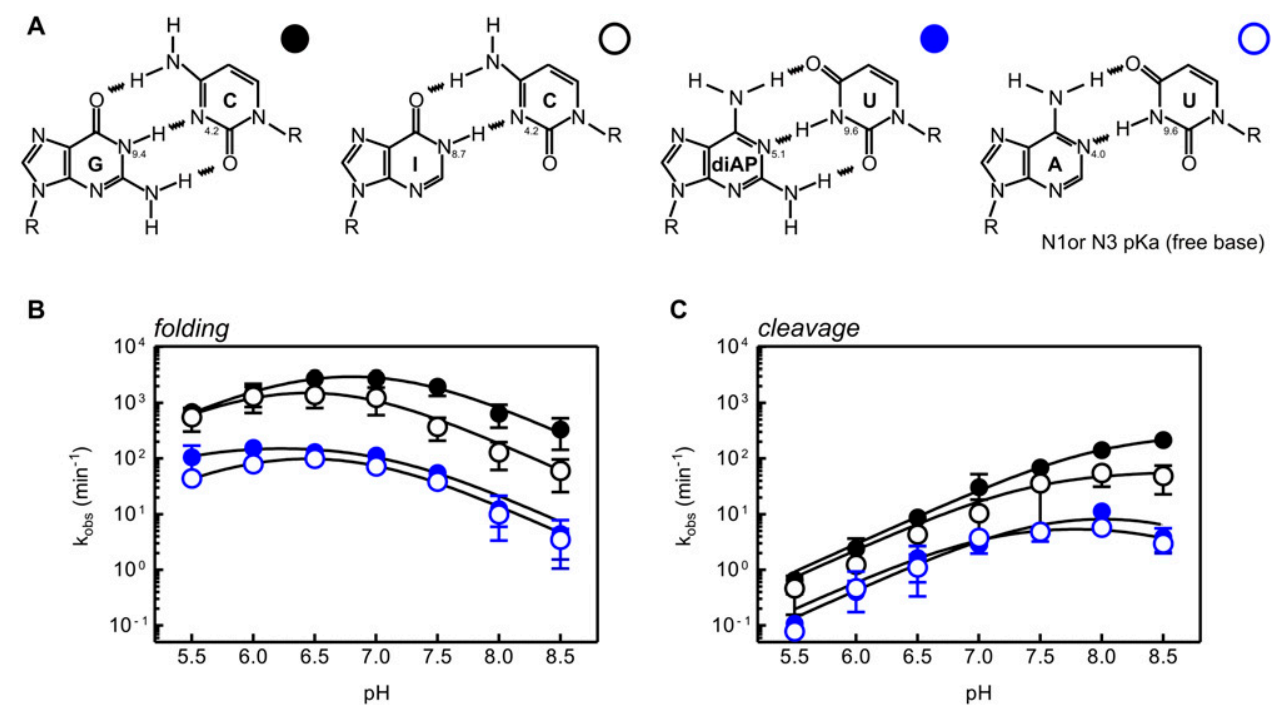

FIGURE 4. Comparison of $\mathrm{pH}$ dependence of cleavage and folding for the $S$. mansoni hammerhead ribozyme and its G8-C3 base pair WatsonCrick analogs. (A) Structure of the G8-C3 Watson-Crick base pair (black circle) and analog pairs of I8-C3 (open, black circles), diAP8-U3 (blue circles), and A8-U3 (open, blue circles). The respective $\mathrm{pK}_{\mathrm{a}}$ values of $\mathrm{N} 1$ of purines and $\mathrm{N} 3$ of pyrimidines are highlighted. (B) pH-dependent folding as monitored by fluorescence change of core pyC7 of G8-C3 and analog base pair variants. The folding data were acquired, fitted, and plotted as described for G8-C3 folding in Figure 3 and Materials and Methods. Each of the analyzed variants yielded two apparent pK $\mathrm{s}$ of folding: $6.1( \pm 0.3)$ and $6.8( \pm 0.2)$ for I8-C3; $5.5( \pm 0.1)$ and $7.1( \pm 0.2)$ for diAP8-U3; $5.9( \pm 0.1)$ and $6.9( \pm 0.1)$ for A8-U3 as compared with $6.3( \pm 0.2)$ and $7.4( \pm 0.1)$ for G8-C3. $(C)$ pH-dependent cleavage assays were performed under single turnover conditions with the same buffer, salt, and $\mathrm{Mg}^{2+}$ concentrations as described for folding experiments in Figure 3. The resulting apparent rate constants for cleavage were plotted as a function of $\mathrm{pH}$ and fitted to the Henderson-Hasselbalch equation yielding one apparent $\mathrm{pK}_{\mathrm{a}}$ value of $8.4( \pm 0.2)$ for G8-C3 and 8.0 ( \pm 0.2$)$ for I8-C3. For diAP8-U3 and A8-U3, the $\mathrm{pH}$ dependence of cleavage resembles a bell-shaped profile, and curve fitting yielded two pK $\mathrm{a}_{\mathrm{a}}$. The best fit was obtained when the second $\mathrm{pK}_{\mathrm{a}}$ was constrained to $>8.5$ and then the fit yielded the upright $\mathrm{pK}$ of $7.5( \pm 0.3)$ for diAP8-U3, 7.0 ( \pm 0.2$)$ for A8-U3. For the clarity of the graphs, we have displayed only every $0.5 \mathrm{pH}$ unit datum. For the very low and high $\mathrm{pH}$ conditions, the cleavage and folding were performed in smaller increments than displayed. (Instead of $0.5 \mathrm{pH}$ unit, 0.2 increments were tested, starting at $\mathrm{pH} 5$ and ending at $\mathrm{pH} 9$, respectively. $\mathrm{pH} 9$ and 5 were not included in the fit.) The values are summarized in Tables 1-3.

Table 1). Fitting the cleavage data to a Henderson-Hasselbalch equation yields an apparent $\mathrm{pK}_{\mathrm{a}}$ of $8.4( \pm 0.1)$ for the G8-C3 and a slightly lower value of $8.0( \pm 0.2)$ for I8-C3 (Table 3, below). Although the difference between the $\mathrm{pK}_{\mathrm{a}} \mathrm{s}$ is small, these results appear to be consistent with the direction of the $\mathrm{pK}_{\mathrm{a}}$ difference between the two nucleobases in solution (9.4 for G and 8.5 for I, respectively) (Brown 1971).

To further probe the folding versus activity dependence of the G8-C3 base pair on $\mathrm{pH}$, we examined two additional base pairs with reversed $\mathrm{pK}_{\mathrm{a}}$ : low on purine and high on pyrimidine. We decided on pairs of adenosine $\left(\mathrm{A}, \mathrm{pK}_{\mathrm{a}} 4.0\right)$ and 2,6-diaminopurine (diAP, $\mathrm{pK}_{\mathrm{a}}$ 5.1) combined with uracil $\left(\mathrm{U}, \mathrm{pK}_{\mathrm{a}}\right.$ 9.6) (Fig. 4A). The diAP-U base pair forms three hydrogen bonds in a base pair analogous to the Watson-Crick G-C (Kyogoku et al. 1967; Jorgensen and Pranata 1990), and A-U is structurally and thermodynamically analogous to the Watson-Crick base pair of I-C, containing two hydrogen bonds (Fig. 4A). Since both diAP and A have low $\mathrm{pK}_{\mathrm{a}}$ as compared with $\mathrm{G}$ (Brown 1971), we would expect the folding to be $\mathrm{pH}$-independent at high $\mathrm{pH}$ values, but only if the protonation of the purine is functionally relevant to folding. With the restoration of an isosteric base pair containing three hydrogen bonds for diAP8-U3, we anticipated restoring the reaction rate to that of the wild-type construct.
The pH-dependent folding of diAP8-U3 and A8-U3 variants monitored by pyC7 displayed a similarity to the unmodified ribozyme fluorescence increase at low $\mathrm{pH}$ and $50 \%$ lower at high $\mathrm{pH}$. Both the rates of folding (Fig. 4B) and the associated amplitudes (Table 1) of fluorescence change for each variant are nearly $\mathrm{pH}$-independent up to $\mathrm{pH} 7.0$ and linearly decrease as a function of $\mathrm{pH}$. The rates of folding are on average 10-20 times slower than that of the unmodified ribozyme and reach a minimum at $\mathrm{pH} 8.5$ of $4.4 \mathrm{~min}^{-1}( \pm 0.5)$ for diAP8-U3 and $3.5 \mathrm{~min}^{-1}( \pm 0.4)$ for A8-U3 (Fig. 4B; Table 1). The $\mathrm{pH}$-dependent cleavage of A8-U3 and diAP8-U3 at low $\mathrm{pH}$ is on average five times slower from that of G8-C3 and I8-C3. The difference increases to $\sim 50$-fold at high $\mathrm{pH}$. Both variants reach a maximum rate of cleavage at $\mathrm{pH}$ 8.0: $11 \mathrm{~min}^{-1}( \pm 1)$ for diAP8-U3 and $5.8 \mathrm{~min}^{-1}( \pm 0.8)$ for A8-U3). At $\mathrm{pH} 8.5$, both variants display a decrease in the cleavage rate that parallels that of folding (Fig. 4B,C; Table 1).

Given that the $\mathrm{pH}$ profile of cleavage for the diAP8-U3 and $\mathrm{A} 8 \mathrm{-U} 3$ variants is limited at high $\mathrm{pH}$ by the rate of folding, it is difficult to retrieve an overall single $\mathrm{pK}_{\mathrm{a}}$ of the cleavage reaction for the diAP8-U3 and A8-U3 variants. However, since the activity at low and neutral $\mathrm{pH}$ is loglinear and extends well beyond the predicted $\mathrm{pK}_{\mathrm{a}}$ for diAP 
TABLE 1. Biochemical and fluorescence characterization of S. mansoni hammerhead ribozyme and G8-C3 variants

\begin{tabular}{|c|c|c|c|c|c|c|}
\hline \multirow{2}{*}{$\frac{\text { Variant }}{\mathrm{pH} 5.5}$} & \multicolumn{2}{|c|}{$k_{f}^{\mathrm{a}}\left(\mathrm{min}^{-1}\right)$} & \multirow[t]{2}{*}{$F / F_{0}{ }^{b}$} & \multicolumn{2}{|c|}{$k_{c}{ }^{c}\left(\min ^{-1}\right)$} & \multirow[t]{2}{*}{$F_{C}{ }^{d}$} \\
\hline & & & & & & \\
\hline G8C3 & 684 & (144) & 1.33 & 0.65 & $(0.08)$ & 0.68 \\
\hline I8C3 & 555 & (125) & 1.34 & 0.46 & (0.05) & 0.63 \\
\hline diAP8U3 & 105 & (13) & 1.32 & 0.11 & $(0.01)$ & 0.46 \\
\hline A8U3 & 44 & (8) & 1.32 & 0.08 & $(0.01)$ & 0.58 \\
\hline G8U3 & 948 & (87) & 1.52 & 0.06 & $(0.01)$ & 0.64 \\
\hline A8C3 & 23 & (3) & 1.31 & 0.11 & $(0.02)$ & 0.55 \\
\hline diAP8C3 & 11 & (1) & 1.30 & 0.09 & $(0.01)$ & 0.30 \\
\hline \multicolumn{7}{|l|}{ pH 6.0} \\
\hline G8C3 & 1509 & (312) & 1.30 & 2.4 & $(0.1)$ & 0.70 \\
\hline I8C3 & 1297 & $(274)$ & 1.35 & 1.2 & $(0.1)$ & 0.67 \\
\hline diAP8U3 & 155 & (12) & 1.32 & 0.40 & $(0.09)$ & 0.50 \\
\hline A8U3 & 80 & (7) & 1.30 & 0.47 & $(0.11)$ & 0.64 \\
\hline G8U3 & 1248 & $(231)$ & 1.48 & 0.53 & $(0.04)$ & 0.58 \\
\hline A8C3 & 73 & (9) & 1.30 & 0.28 & $(0.03)$ & 0.56 \\
\hline diAP8C3 & 31 & (4) & 1.28 & 0.40 & $(0.05)$ & 0.31 \\
\hline \multicolumn{7}{|l|}{ pH 6.5} \\
\hline G8C3 & 2739 & (338) & 1.35 & 8.7 & (1.1) & 0.64 \\
\hline I8C3 & 1380 & (189) & 1.38 & 4.3 & $(0.7)$ & 0.57 \\
\hline diAP8U3 & 131 & (10) & 1.34 & 1.6 & $(0.2)$ & 0.52 \\
\hline A8U3 & 99 & $(12)$ & 1.25 & 1.1 & $(0.1)$ & 0.67 \\
\hline G8U3 & 1152 & $(160)$ & 1.40 & 1.4 & $(0.03)$ & 0.64 \\
\hline A8C3 & 75 & (11) & 1.26 & 1.1 & (0.09) & 0.48 \\
\hline diAP8C3 & 38 & (3) & 1.22 & 0.8 & $(0.06)$ & 0.30 \\
\hline \multicolumn{7}{|l|}{ pH 7.0} \\
\hline G8C3 & 2745 & (165) & 1.43 & 31 & (6) & 0.61 \\
\hline I8C3 & 1235 & (111) & 1.52 & 10 & (2) & 0.59 \\
\hline diAP8U3 & 113 & (9) & 1.30 & 2.9 & $(0.3)$ & 0.50 \\
\hline A8U3 & 73 & (13) & 1.18 & 3.7 & $(0.3)$ & 0.62 \\
\hline G8U3 & 810 & (112) & 1.32 & 3.3 & $(0.1)$ & 0.70 \\
\hline A8C3 & 60 & (7) & 1.18 & 1.6 & $(0.1)$ & 0.53 \\
\hline diAP8C3 & 25 & (2) & 1.12 & 1.4 & $(0.1)$ & 0.30 \\
\hline \multicolumn{7}{|l|}{ pH 7.5} \\
\hline G8C3 & 1954 & (130) & 1.32 & 69 & (4) & 0.52 \\
\hline I8C3 & 373 & $(82)$ & 1.44 & 36 & (5) & 0.45 \\
\hline diAP8U3 & 55 & (4) & 1.24 & 5.0 & $(0.7)$ & 0.44 \\
\hline A8U3 & 38 & (5) & 1.11 & 4.8 & (0.4) & 0.75 \\
\hline G8U3 & 312 & $(42)$ & 1.20 & 6.4 & $(0.5)$ & 0.61 \\
\hline A8C3 & 27 & (2) & 1.13 & 2.2 & $(0.3)$ & 0.48 \\
\hline diAP8C3 & 16 & (1) & 1.08 & 1.5 & $(0.1)$ & 0.54 \\
\hline \multicolumn{7}{|l|}{ pH 8.0} \\
\hline G8C3 & 640 & (61) & 1.28 & 141 & (12) & 0.42 \\
\hline I8C3 & 128 & (38) & 1.36 & 55 & (5) & 0.41 \\
\hline diAP8U3 & 13 & (1) & 1.15 & 11 & (2) & 0.32 \\
\hline A8U3 & 10 & (1) & 1.07 & 5.8 & $(0.8)$ & 0.64 \\
\hline G8U3 & 120 & (14) & 1.14 & 9.2 & $(0.7)$ & 0.58 \\
\hline A8C3 & 14 & (2) & 1.08 & 1.8 & $(0.2)$ & 0.52 \\
\hline diAP8C3 & 8.4 & $(0.5)$ & 1.05 & 1.0 & $(0.1)$ & 0.48 \\
\hline \multicolumn{7}{|l|}{ pH 8.5} \\
\hline G8C3 & 334 & (81) & 1.22 & 214 & $(27)$ & 0.31 \\
\hline 18C3 & 61 & (10) & 1.27 & 49 & (6) & 0.30 \\
\hline diAP8U3 & 4.4 & $(0.5)$ & 1.09 & 3.8 & (0.6) & 0.31 \\
\hline A8U3 & 3.5 & $(0.4)$ & 1.04 & 3.0 & $(0.3)$ & 0.64 \\
\hline
\end{tabular}

and $\mathrm{A}(\sim 5)$, these data suggest that it is not the identity and the $\mathrm{pK}_{\mathrm{a}}$ of the $\mathrm{N} 1$ of the purine at position 8 that is important for ribozyme catalysis, but rather the stability of the interaction with pyrimidine at position 3. Moreover, these data suggest that introduction of uracil at position 3 destabilizes the active fold or, alternatively, stabilizes the ground state.

\section{Rescue of deleterious G8-C3 mutations at low pH}

We previously showed for the minimal hammerhead ribozyme that introduction of diAP at position 8 (diAP8-C3) strongly inhibited and altered the $\mathrm{pH}$-dependent profile of cleavage, reducing the rate by more than three orders of magnitude (Han and Burke 2005). Although the diAP8-C3 (Fig. 5A) mutation in the native ribozyme has a surprisingly smaller impact on activity, it does have an effect on the $\mathrm{pH}$ profile of folding and activity (Fig. 5B,C). Folding analysis of the diAP8-C3 variant shows that the maximum velocity of $38 \mathrm{~min}^{-1}( \pm 3)$ is reached at $\mathrm{pH} 6.5$ (Fig. 5B; Table 1), and the amplitude of the fluorescence is similar to that of the wild type (Table 1). The rates of folding and the apparent amplitudes significantly decrease with higher $\mathrm{pH}$ and reach a minimum at $\mathrm{pH} 8.5$ (Fig. 5B; Table 1). Although the fluorescence change is small at high $\mathrm{pH}$, an average of five to 10 transients gave a signal-to-noise ratio that was sufficient for reliable single exponential fitting. The cleavage rate for diAP8-C3 increases over the range of $\mathrm{pH}$ 5.56.5 , with rates less than two times slower than those of the unmodified ribozyme, levels off at $\mathrm{pH} 7.5$, and then decreases as the $\mathrm{pH}$ is raised (Fig. 5C). The bell-shaped $\mathrm{pH}$ profile for the diAP8-C3 cleavage reaction could be fitted with $\mathrm{pK}_{\mathrm{a}}$ values of $6.7( \pm 0.4)$ and $8.1( \pm 0.3)$ (Fig. 5C; Table 3, below). Structurally, diAP has been shown to form either an unstable one-hydrogen-bond wobble-like base pair with cytosine at neutral $\mathrm{pH}$ or, strengthened by N1 protonation of diAP, a two-hydrogen-bond base pair (Strobel et al. 1994), thermodynamically equivalent to a two-hydrogen-bond A-U base pair. In fact, diAP8-C3 folds and cleaves at moderate $\mathrm{pH}$ with the same rate and to the same extent (Fig. $5 \mathrm{~B}, \mathrm{C}$ ) as Watson-Crick A8-U3 (Fig. 4A).

To test the hypothesis that the rescue of the diAP8 mutation may be due to the formation of a protonated wobble-like base pair depending on the $\mathrm{pK}_{\mathrm{a}}$ of the purine, we examined the A8-C3 and G8-U3 variants (Fig. 5A). Protonated adenosine has been shown to form a stable twohydrogen-bond wobble-like pair with cytosine, isosteric to diAP $^{+}-\mathrm{C}$ and G-U wobble pairs (Doudna et al. 1989). Our results (Fig. 5B,C) show that the ribozyme with the A8-C3 mutation has $\mathrm{pH}$-dependent levels of activity and folding similar to those of the diAP8-C3 pair (Fig. 5B,C; Table 1). Since protonated wobble-like 8-3 base pairs were able to rescue the activity to a level similar to that of the unmodified ribozyme, we further expected the G8-U3 (Fig. 5A) mutant 
TABLE 1. Continued

\begin{tabular}{lcccccc}
\hline Variant & \multicolumn{1}{c}{$k_{f}{ }^{\mathrm{a}}\left(\mathrm{min}^{-1}\right)$} & $F / F_{0}{ }^{\mathrm{b}}$ & \multicolumn{2}{c}{$k_{c}{ }^{\mathrm{c}}\left(\mathrm{min}^{-1}\right)$} & $F_{c}{ }^{\mathrm{d}}$ \\
\hline G8U3 & 48 & $(12)$ & 1.09 & 6.2 & $(0.6)$ & 0.57 \\
A8C3 & 2.8 & $(0.2)$ & 1.05 & 1.0 & $(0.1)$ & 0.50 \\
diAP8C3 & 4.8 & $(0.2)$ & 1.03 & 0.6 & $(0.1)$ & 0.50 \\
\hline
\end{tabular}

Core folding (position pyC7) and cleavage activity were determined in the presence of $50 \mathrm{mM}$ buffer salt adequate to $\mathrm{pH}$ (see Materials and Methods) and $100 \mathrm{mM} \mathrm{NaCl}$, at $25^{\circ} \mathrm{C}$ upon mixing with $\mathrm{MgCl}_{2}$ (10 mM final concentration). Each parameter reported here is the average of at least four independent determinations. Experiments conducted side-by-side display a high degree of precision for fluorescence amplitude $\left(<5 \%\right.$ variation in $F / F_{0}$ and $F_{\mathrm{c}}$ ), while the variation in rate constants was slightly larger (usually $<15 \%)$. The experiments performed with different ribozyme preparations and different sets of buffers showed only $10 \%$ of deviation one to another.

${ }^{a}$ Apparent rate constant for the formation of the folded intermediate. ${ }^{\mathrm{b}} \mathrm{F} / F_{0}$ is the ratio of the fluorescence of the folded intermediate $(F)$ and the starting fluorescence $\left(F_{0}\right)$ of the ground-state ribozyme complex in the absence of $\mathrm{MgCl}_{2}$.

${ }^{\mathrm{c}}$ Apparent single turnover rate constant of cleavage.

${ }^{\mathrm{d}}$ Fraction of cleaved substrate.

to behave similarly to the wild type. Interestingly, G8-U3 (Fig. 5B,C; Table 1) behaves rather similarly to the WatsonCrick diAP8-U3 and A8-U3 variants, indicating that its activity and folding may be affected by the pyrimidine in those pairs, U3. cation with the critical G8 residue, the $\mathrm{pH}$-dependent profile of cleavage activity and folding of both single and double mutations of the respective positions were measured.

Core folding of the unmodified minimal ribozyme occurred at an overall one-order-of-magnitude-slower rate compared with the natural ribozyme. In contrast to the natural ribozyme, where folding was clearly $\mathrm{pH}$-dependent (bell shaped), there are only minor differences between the rate of folding at low, neutral, and high $\mathrm{pH}$ for the minimal ribozyme (Fig. 6A,C; Table 2). Further differences between minimal and natural ribozymes could be observed for the single diAP8 variant. In the minimal ribozyme, this mutation showed more than five orders of magnitude inhibition of folding, whereas the same mutation in the natural ribozyme led to a decrease in the rate of folding of no more than two orders of magnitude (Fig. 6A,C; Table 2). Interestingly, the rate of folding for single diAP12 variant was only slightly influenced. For the minimal ribozyme, the difference was mostly manifested at low and high $\mathrm{pH}$ (fivefold decrease), whereas for the natural ribozyme, the decrease in the rate of folding was on average only twofold lower at each pH studied (Fig. 6A,C; Table 2).

As shown in Figure 6, B and D, the minimal ribozyme exhibited an average of a 10-30-fold decrease in cleavage activity as compared with natural ribozyme at each $\mathrm{pH}$ studied. Single diAP12 substitutions showed a comparable

\section{Double G8 and G12 mutations in minimal versus native hammerhead ribozyme}

Our previously published studies demonstrated that a simultaneous substitution of the two important nucleobases G8 and G12 with 2,6-diaminopurine shifts the $\mathrm{pH}$ optimum of the cleavage reaction from $>8.5$ (linear) to $\sim 6.8$ (bell shaped) in two different hammerhead ribozymes (Han and Burke 2005). On the basis of pH-activity studies of targeted variants and zero-length photocross-linking analysis, we proposed that G8 and G12 are catalytic nucleotides within the hammerhead's active site (Han and Burke 2005; Heckman et al. 2005; Lambert et al. 2006). Subsequent crystallographic studies of Scott and colleagues (Martick and Scott 2006; Chi et al. 2008; Martick et al. 2008) are broadly consistent with this hypothesis. However, in order to interpret simultaneously the role of G12 in folding and catalysis and to determine its communi-
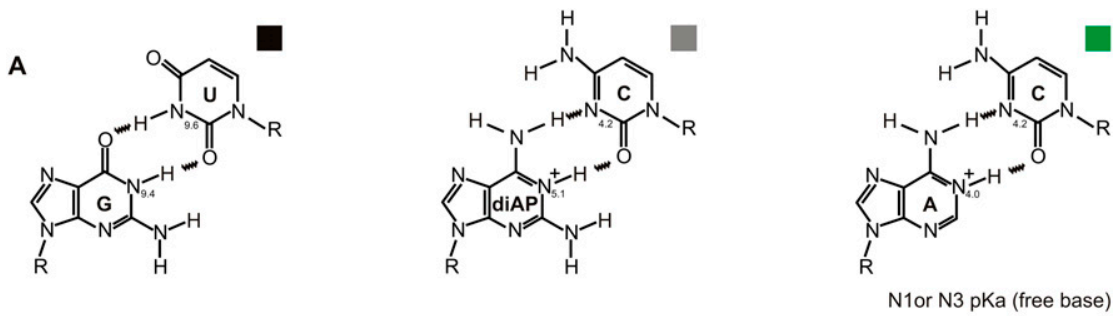

B

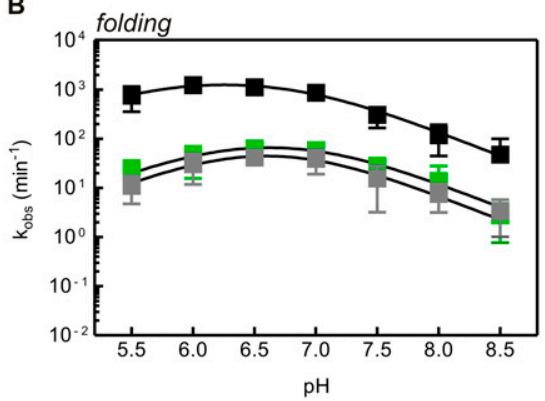

C

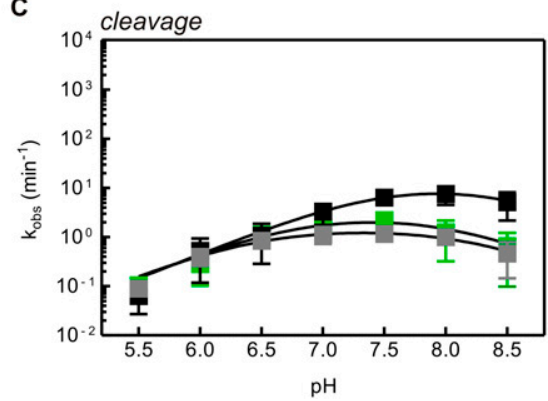

FIGURE 5. The $\mathrm{pH}$ dependence of cleavage and folding for wobble-like 8-3 base-pair variants. (A) G8-U3 (black squares), diAP8-C3 (gray squares), and A8-C3 (green squares) (B) $\mathrm{pH}$ dependent folding as monitored by the fluorescence change of pyC7 of wobble-like 8-3 base-pair analogs. The data were acquired, fitted, and plotted as described for G8-C3 folding in Figure 4. Folding of the analyzed variants yielded a bell-shaped $\mathrm{pH}$ profile, and fit resulted in two apparent $\mathrm{pK}_{\mathrm{a}} \mathrm{s}$ of folding of $5.5( \pm 0.3)$ and $6.9( \pm 0.2)$ for G8-U3; $6.1( \pm 0.6)$ and $6.9( \pm 0.3)$ for diAP8-C3; $6.2( \pm 0.4)$ and $6.7( \pm 0.5)$ for $\mathrm{A} 8-\mathrm{C} 3 .(C) \mathrm{pH}$-dependent cleavage assays were performed as described for 8-3 analogs in Figure 4. $\mathrm{pH}$ dependence of cleavage for each of the analyzed variants yielded a bell-shaped profile, and curve fitting revealed two apparent $\mathrm{pK}_{\mathrm{a}} \mathrm{s}$ of $7.9( \pm 0.4)$ and $>8.5$ for G8-U3; $6.7( \pm 0.4)$ and $8.1( \pm 0.3)$ for diAP8-C3; $6.9( \pm 0.2)$ and $8.1( \pm 0.3)$ for A8-C3. 

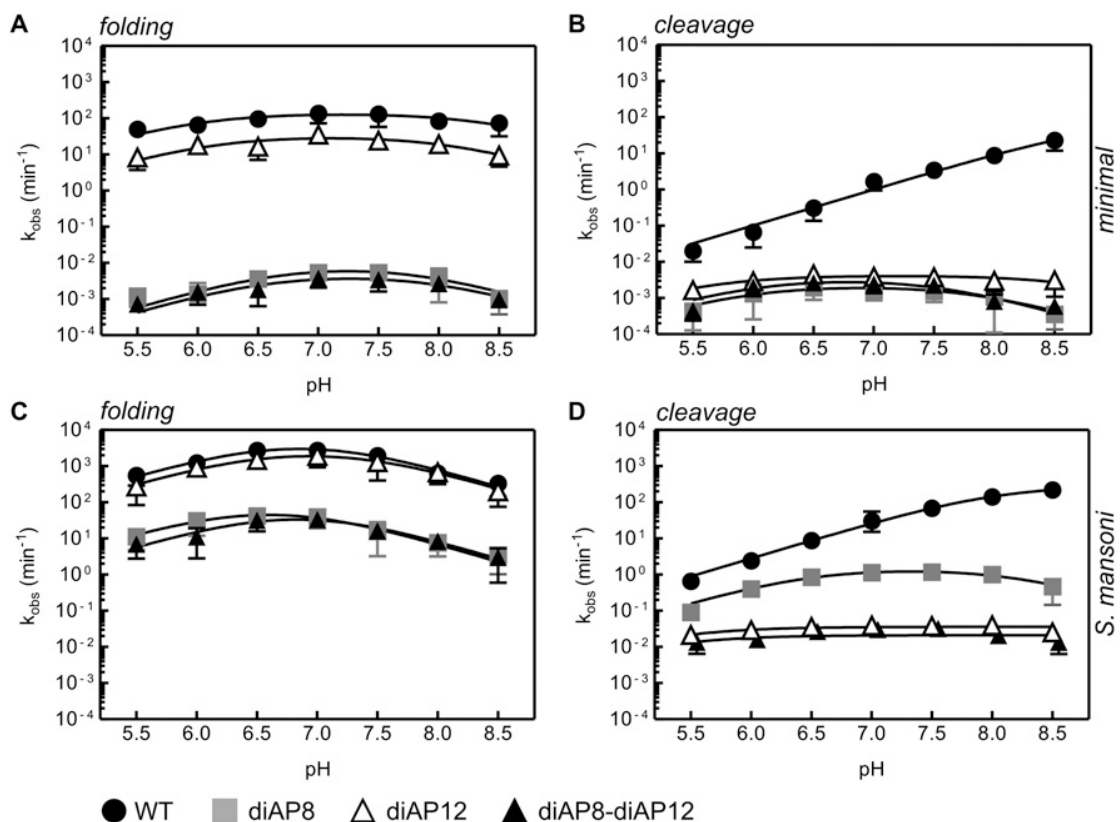

FIGURE 6. Comparison of pH-dependent core folding and cleavage of unmodified G8 (closed, black circle), diAP8 (closed, gray squares), diAP12 (open, black triangle), and double diAP8diAP12 (black triangle) in the background of both minimal $(A, B)$ and natural $(C, D) S$. mansoni hammerhead ribozyme. The $\mathrm{pH}$-dependent core folding (pyC7) was performed as described in Figure 3. Folding of the analyzed minimal ribozyme and variants yielded an almost-flat $\mathrm{pH}$ profile, where the differences between high, moderate, and low $\mathrm{pH}$ did not exceed twofold, and fit resulted in two apparent $\mathrm{pK}_{\mathrm{a}} \mathrm{s}$ of folding that are rather approximations of $\sim 5.5( \pm 1.7)$ and $8.5( \pm 0.9)$ for G8-G12; $\sim 6.0( \pm 1.5)$ and $8.0( \pm 0.9)$ for diAP12; 6.2 $( \pm 1.4)$ and $8.0( \pm 0.9)$ for diAP8; and $\sim 6.2( \pm 1.3)$ and $8.0( \pm 1.4)$ for diAP8-diAP12. The same experiments performed in the background of the natural ribozyme yielded $\mathrm{pK}_{\mathrm{a}} \mathrm{s}$ of 6.3 $( \pm 0.2)$ and $7.4( \pm 0.1)$ for G8-G12; $6.5( \pm 0.4)$ and $7.4( \pm 0.5)$ for diAP12; $6.1( \pm 0.6)$ and 6.9 $( \pm 0.3)$ for diAP8; $6.2( \pm 0.3)$ and $6.9( \pm 0.5)$ for diAP8-diAP12. The pH-dependent cleavage reactions of minimal $(B)$ and natural $(D)$ ribozymes were performed as described in Figure 4. The $\mathrm{pH}$-dependent cleavage for unmodified minimal ribozyme is $\log$ linear with $\mathrm{pK}_{\mathrm{a}}$ higher than 9. Cleavage of the minimal ribozyme single and double G8-G12 variants yielded bellshaped $\mathrm{pH}$ profiles and resulted in two apparent $\mathrm{pK}_{\mathrm{a}} \mathrm{s}: 5.7( \pm 0.4)$ and $8.5( \pm 0.3)$ for diAP12; $6.1( \pm 0.3)$ and $7.7( \pm 0.3)$ for diAP8; $5.9( \pm 0.2)$ and $7.7( \pm 0.6)$ for diAP8-diAP12. The same $\mathrm{pH}$ profiles for natural ribozyme yielded a log-linear activity increase for unmodified ribozyme with a slight leveling off at $\mathrm{pH} 8.5$, yielding an apparent $\mathrm{pK}_{\mathrm{a}}$ of $8.4( \pm 0.2)$. The single diAP8 mutation showed a bell-shaped profile of cleavage, which resulted in apparent $\mathrm{pK}_{\mathrm{a}} \mathrm{s}$ of 6.7 $( \pm 0.4)$ and $8.1( \pm 0.3)$. Both single diAP12 and double diAP8-diAP12 variants showed too small differences in cleavage across the analyzed $\mathrm{pH}$ (twofold) to obtain reliable fit; consequently, the $\mathrm{pK}_{\mathrm{a}} \mathrm{s}$ were assigned to be $<5.5$ and $>8.5$. For clarity of the graph, the cleavage values for diAP8-diAP12 were incremented by $0.05 \mathrm{pH}$ unit.

decrease in activity in both minimal and natural ribozymes as compared with unmodified versions: one order of magnitude at low $\mathrm{pH}$, two to three orders at neutral, and nearly four orders of magnitude at high $\mathrm{pH}$, respectively (Fig. 6B,D; Table 2). The difference among the cleavage activities at low, neutral, and basic $\mathrm{pH}$ for both ribozymes did not exceed twofold; therefore, the pH profile is nearly level (Fig. 6B). Interestingly, a single diAP8 substitution showed differences in the cleavage decrease between both ribozymes. For the minimal ribozyme, this mutation caused decrease in cleavage rate of one order of magnitude at low $\mathrm{pH}$, three orders at neutral $\mathrm{pH}$, to more than four orders of magnitude at $\mathrm{pH} 8.5$ (Fig. 6B; Table 2). In contrast, in the native hammerhead, the same substitution caused a decrease in cleavage, ranging from only less than one order of magnitude at low and neutral $\mathrm{pH}$ to two orders of magnitude at basic pH (Fig. 6D; Table 2). Furthermore, the cleavage rates of single diAP8 variant in the minimal ribozyme somewhat parallel those of folding at each $\mathrm{pH}$ studied, while those for the natural ribozyme are only similar to folding rates at $\mathrm{pH} 8$ and 8.5 (Fig. 6A-D).

A comparison of the cleavage and folding rates of the minimal and native double diAP8-diAP12 ribozyme variants showed that the $\mathrm{pH}$ dependence of cleavage activity is restricted in both of these ribozymes by different residues (Fig. 6A-D). In the minimal ribozyme, the $\mathrm{pH}$-dependent cleavage activity of diAP8-diAP12 is comparable to rates of both cleavage and folding of the single diAP8 variant, whereas for the native ribozyme, the activity of the double diAP8diAP12 ribozyme is analogous only to the rate of cleavage of a single diAP12 variant (Fig. 6C,D). Together, these results are consistent with a model in which the $\mathrm{pH}$-dependent activity of the double diAP8-diAP12 variant in the minimal ribozyme is folding-limited, whereas the $\mathrm{pH}$-dependent activity of the same variant in the native ribozyme derives from the shift of the $\mathrm{pK}_{\mathrm{a}}$ of the $\mathrm{N} 1$ proton or/ and the exchange of the O6 carbonyl to the amino group of the G12 residue.

\section{DISCUSSION}

The fluorescence of pyC provides an attractive tool for the analysis of reaction states and their dynamics in nucleic acids at specific sites. Our realtime fluorescence assay permitted us to follow topologically the kinetics of both global and local conformational changes in the folding pathway of the hammerhead ribozyme. For the first time, we were able to show that the native hammerhead ribozyme, like its more extensively studied minimal counterpart, follows not a single, but at least a two-step folding pathway with at least two distinct $\mathrm{Mg}^{2+}$ dependencies for core and global folding, each of which is one order of magnitude lower than those observed for the minimal hammerhead version (Penedo et al. 2004; Kim et al. 2005). The reason why the two previous FRET and SMD (single molecule detection) studies on the natural hammerhead ribozyme folding (Penedo et al. 2004; Boots 
TABLE 2. Biochemical and fluorescence characterization of minimal ( $\mathrm{min})$ and $S$. mansoni $(\mathrm{Sm})$ hammerhead ribozyme with G8-G12 variants

\begin{tabular}{|c|c|c|c|c|c|c|c|}
\hline \multirow{2}{*}{$\frac{\text { Variant }}{\mathrm{pH} 5.5}$} & & \multicolumn{2}{|c|}{$k_{f}{ }^{\mathrm{a}}\left(\min ^{-1}\right)$} & \multirow[t]{2}{*}{$F / F_{0}{ }^{b}$} & \multicolumn{2}{|c|}{$k_{c}{ }^{\mathrm{C}}\left(\min ^{-1}\right)$} & \multirow[t]{2}{*}{$F_{C}{ }^{d}$} \\
\hline & & & & & & & \\
\hline Sm & G8G12 & 684 & (144) & 1.33 & 0.65 & $(0.08)$ & 0.68 \\
\hline & diAP8 & 11 & (1) & 1.30 & 0.09 & $(0.01)$ & 0.30 \\
\hline & diAP12 & 272 & (56) & 1.32 & 0.021 & $(0.002)$ & 0.10 \\
\hline & diAP8-12 & 9 & (1) & 1.27 & 0.021 & $(0.003)$ & 0.17 \\
\hline $\min$ & G8G12 & 72 & (12) & 1.15 & 0.020 & $(0.001)$ & 0.84 \\
\hline & diAP8 & 0.0015 & $(0.0002)$ & 1.11 & 0.0005 & $(0.0001)$ & 0.76 \\
\hline & diAP12 & 11 & (1) & 1.13 & 0.0017 & $(0.0003)$ & 0.54 \\
\hline & diAP8-12 & 0.0007 & $(0.0001)$ & 1.09 & 0.0004 & $(0.0001)$ & 0.61 \\
\hline \multicolumn{8}{|l|}{ pH 6.0} \\
\hline \multirow[t]{4}{*}{ Sm } & G8G12 & 1509 & (312) & 1.30 & 2.4 & $(0.1)$ & 0.70 \\
\hline & diAP8 & 31 & (4) & 1.28 & 0.40 & $(0.02)$ & 0.31 \\
\hline & diAP12 & 900 & (76) & 1.30 & 0.029 & $(0.002)$ & 0.12 \\
\hline & diAP8-12 & 21 & $(2)$ & 1.25 & 0.022 & (0.004) & 0.19 \\
\hline \multirow[t]{4}{*}{$\min$} & G8G12 & 90 & (4) & 1.17 & 0.08 & $(0.01)$ & 0.80 \\
\hline & diAP8 & 0.003 & $(0.007)$ & 1.10 & 0.0015 & $(0.0003)$ & 0.75 \\
\hline & diAP12 & 21 & $(0.4)$ & 1.11 & 0.0029 & $(0.0005)$ & 0.58 \\
\hline & diAP8-12 & 0.0025 & $(0.0003)$ & 1.10 & 0.0020 & $(0.0004)$ & 0.63 \\
\hline \multicolumn{8}{|l|}{ pH 6.5} \\
\hline \multirow[t]{4}{*}{ Sm } & G8G12 & 2739 & (338) & 1.35 & 8.7 & (1.1) & 0.64 \\
\hline & diAP8 & 38 & (3) & 1.22 & 0.80 & $(0.06)$ & 0.30 \\
\hline & diAP12 & 1478 & (198) & 1.34 & 0.035 & -0.01 & 0.15 \\
\hline & diAP8-12 & 43 & (2) & 1.24 & 0.027 & (0.005) & 0.24 \\
\hline \multirow[t]{4}{*}{$\min$} & G8G12 & 114 & (12) & 1.17 & 0.35 & (0.09) & 0.78 \\
\hline & diAP8 & 0.0036 & $(0.0007)$ & 1.09 & 0.0027 & $(0.0006)$ & 0.73 \\
\hline & diAP12 & 24 & (1) & 1.10 & 0.0045 & $(0.0009)$ & 0.57 \\
\hline & diAP8-12 & 0.0031 & $(0.0005)$ & 1.08 & 0.0027 & $(0.0005)$ & 0.60 \\
\hline \multicolumn{8}{|l|}{ pH 7.0} \\
\hline \multirow[t]{4}{*}{ Sm } & G8G12 & 2745 & (165) & 1.43 & 31 & (6) & 0.61 \\
\hline & diAP8 & 25 & (2) & 1.12 & 1.4 & $(0.1)$ & 0.30 \\
\hline & diAP12 & 1920 & (121) & 1.38 & 0.039 & $(0.007)$ & 0.21 \\
\hline & diAP8-12 & 34 & (6) & 1.11 & 0.030 & (0.005) & 0.28 \\
\hline \multirow[t]{4}{*}{$\min$} & G8G12 & 138 & (8) & 1.16 & 1.30 & $(0.03)$ & 0.76 \\
\hline & diAP8 & 0.0054 & $(0.0005)$ & 1.07 & 0.0022 & $(0.0004)$ & 0.73 \\
\hline & diAP12 & 36 & (4) & 1.14 & 0.0039 & $(0.0006)$ & 0.56 \\
\hline & diAP8-12 & 0.0038 & $(0.0006)$ & 1.08 & 0.0024 & $(0.0003)$ & 0.62 \\
\hline \multicolumn{8}{|l|}{ pH 7.5} \\
\hline \multirow[t]{4}{*}{ Sm } & G8G12 & 1954 & (130) & 1.32 & 69 & (4) & 0.52 \\
\hline & diAP8 & 16 & (1) & 1.08 & 1.5 & $(0.1)$ & 0.54 \\
\hline & diAP12 & 1290 & (167) & 1.30 & 0.038 & (0.004) & 0.24 \\
\hline & diAP8-12 & 16 & (1) & 1.09 & 0.033 & $(0.007)$ & 0.31 \\
\hline \multirow[t]{4}{*}{$\min$} & G8C3 & 126 & (9) & 1.12 & 3.7 & $(0.9)$ & 0.70 \\
\hline & diAP8 & 0.0054 & $(0.0007)$ & 1.07 & 0.0021 & $(0.0004)$ & 0.69 \\
\hline & diAP12 & 24 & (1) & 1.13 & 0.0038 & $(0.0006)$ & 0.52 \\
\hline & diAP8-12 & 0.0034 & $(0.0001)$ & 1.08 & 0.0023 & $(0.0003)$ & 0.61 \\
\hline \multicolumn{8}{|l|}{ pH 8.0} \\
\hline Sm & G8G12 & 640 & (61) & 1.28 & 141 & (12) & 0.42 \\
\hline & diAP8 & 8.4 & $(0.5)$ & 1.05 & 1.0 & $(0.1)$ & 0.48 \\
\hline & diAP12 & 680 & (121) & 1.25 & 0.040 & (0.008) & 0.30 \\
\hline & diAP8-12 & 8.3 & $(0.6)$ & 1.07 & 0.029 & (0.006) & 0.36 \\
\hline $\min$ & G8G12 & 96 & (2) & 1.09 & 9.0 & $(0.7)$ & 0.68 \\
\hline & diAP8 & 0.0030 & $(0.0001)$ & 1.08 & 0.0011 & $(0.0003)$ & 0.63 \\
\hline & diAP12 & 19 & (1) & 1.11 & 0.0040 & $(0.0005)$ & 0.50 \\
\hline & diAP8-12 & 0.0027 & $(0.0001)$ & 1.09 & 0.0012 & $(0.0003)$ & 0.60 \\
\hline
\end{tabular}


TABLE 2. Continued

\begin{tabular}{|c|c|c|c|c|c|c|c|}
\hline \multicolumn{2}{|l|}{ Variant } & \multicolumn{2}{|c|}{$k_{f}{ }^{a}\left(\min ^{-1}\right)$} & $F / F_{0}{ }^{b}$ & \multicolumn{2}{|c|}{$k_{c}{ }^{\mathrm{c}}\left(\min ^{-1}\right)$} & \multirow[t]{2}{*}{$F_{C}{ }^{\mathrm{d}}$} \\
\hline \multirow{5}{*}{$\begin{array}{l}\mathrm{pH} 8.5 \\
\text { Sm }\end{array}$} & & & & & & & \\
\hline & G8G12 & 334 & (61) & 1.22 & 214 & $(27)$ & 0.31 \\
\hline & diAP8 & 4.8 & $(0.2)$ & 1.03 & 0.6 & $(0.1)$ & 0.50 \\
\hline & diAP12 & 240 & (29) & 1.18 & 0.025 & $(0.005)$ & 0.35 \\
\hline & diAP8-12 & 4.6 & $(0.3)$ & 1.05 & 0.022 & $(0.005)$ & 0.38 \\
\hline \multirow[t]{4}{*}{$\min$} & G8C3 & 78 & $(0.5)$ & 1.11 & 25 & (2) & 0.69 \\
\hline & diAP8 & 0.0012 & $(0.0003)$ & 1.10 & 0.0005 & $(0.0001)$ & 0.60 \\
\hline & diAP12 & 9 & (1) & 1.14 & 0.0024 & $(0.0003)$ & 0.51 \\
\hline & diAP8-12 & 0.0010 & $(0.0002)$ & 1.11 & 0.0006 & $(0.0001)$ & 0.59 \\
\hline \multicolumn{8}{|c|}{$\begin{array}{l}\text { Core folding (position pyC7) and cleavage activity were determined in the presence of } 50 \mathrm{mM} \text { buffer salt adequate to } \mathrm{pH} \text { (see Materials and } \\
\text { Methods) and } 100 \mathrm{mM} \mathrm{NaCl} \text {, at } 25^{\circ} \mathrm{C} \text { upon mixing with } \mathrm{MgCl}_{2}(10 \mathrm{mM} \text { final concentration). Each parameter reported here is the average of at } \\
\text { least four determinations as described in the legend of Table } 1 \text {. } \\
\text { a Apparent rate constant for the formation of the folded intermediate. } \\
{ }^{\mathrm{b}} \mathrm{F} / \mathrm{F}_{0} \text { is the ratio of the fluorescence of the folded intermediate }(F) \text { and the starting fluorescence }\left(F_{0}\right) \text { of the ground-state ribozyme complex in the } \\
\text { absence of } \mathrm{MgCl}_{2} \text {. } \\
{ }^{c} \text { Apparent single turnover rate constant of cleavage. } \\
\text { dFraction of cleaved substrate. }\end{array}$} \\
\hline
\end{tabular}

et al. 2008; McDowell et al. 2010) failed to identify the twostep folding is because under physiological conditions, both global and core folding are very fast (in the millisecond range) and divided on the time scale by only a few seconds. When $\mathrm{Mg}^{2+}$ is fully saturating, the observed rate constant of the core folding tends toward the intrinsic rate constant of the global transition. Therefore, FRET, sensing only relatively large, global structural changes in terms of the Stem I-Stem II junction distances does not have the capability to detect the fast internal changes in the folding of the core of the natural hammerhead. In the minimal ribozyme, the kinetic and spatial differences of core and global folding are much larger; hence, it was previously possible to dissect them (Bassi et al. 1997; Hammann and Lilley 2002).

Our data on the $\mathrm{Mg}^{2+}$ dependence of the folding show no cooperativity between any sites of the ribozyme studied. This is typical for diffuse binding of $\mathrm{Mg}^{2+}$ by nucleic acids and suggests that charge screening by an ionic atmosphere is required to allow the closer approach of the different parts of the ribozyme (Krakauer 1971; Sander and Ts'o 1971). The rate of cleavage of extended and minimal hammerheads increases with magnesium ion concentration, often without evidence of saturation, and species with higher rates of cleavage show weaker affinity for divalent ions (Clouet-d'Orval and Uhlenbeck 1997; Rueda et al. 2003; Canny et al. 2004). The reason for this behavior is not explainable by a straightforward approach, and it was proposed that the low affinity could partially be due to one or more $\mathrm{Mg}^{2+}$, further increasing the rate with which active conformations occur (Rueda et al. 2003). Our results argue against this model, because the fluorescence data show clear saturation in the observable rate of folding induced by the core $\mathrm{Mg}^{2+}$ binding identified by pyC7 and pyC3, and the fact that the core of the minimal version of the

TABLE 3. Estimation of $\mathrm{pK}_{\mathrm{a}}$ values of $\mathrm{pH}$-dependent folding and cleavage for minimal $(\mathrm{min})$ and natural $S$. mansoni $(\mathrm{Sm})$ ribozymes

\begin{tabular}{|c|c|c|c|c|c|}
\hline \multirow[b]{2}{*}{ Varian } & & \multicolumn{2}{|c|}{ Folding } & \multicolumn{2}{|c|}{ Cleavage } \\
\hline & & $\mathrm{pK}_{\mathrm{a} 1}$ & $\mathrm{pK}_{\mathrm{a} 2}$ & $\mathrm{pK}_{\mathrm{a} 1}$ & $\mathrm{pK}_{\mathrm{a} 2}$ \\
\hline \multirow[t]{9}{*}{ Sm } & G8-C3 (wt) & $6.3(0.2)$ & $7.4(0.1)$ & $8.4(0.2)$ & - \\
\hline & I8-C3 & $6.1(0.3)$ & $6.8(0.2)$ & $8.0(0.2)$ & - \\
\hline & diAP8-U3 & $5.5(0.1)$ & $7.1(0.1)$ & $7.5(0.3)$ & $>8.5^{\mathrm{a}}$ \\
\hline & A8-U3 & $5.9(0.1)$ & $6.9(0.1)$ & $7.0(0.2)$ & $>8.5^{\mathrm{a}}$ \\
\hline & G8-U3 & $5.5(0.3)$ & $6.9(0.2)$ & $7.9(0.4)$ & $>8.5^{\mathrm{a}}$ \\
\hline & diAP8-C3 & $6.1(0.6)$ & $6.9(0.3)$ & $6.7(0.4)$ & $8.1(0.3)$ \\
\hline & A8-C3 & $6.2(0.4)$ & $6.7(0.5)$ & $6.9(0.2)$ & $8.1(0.3)$ \\
\hline & diAP12 & $6.5(0.4)$ & $7.4(0.5)$ & $<5.5^{\mathrm{a}}$ & $>8.5^{\mathrm{a}}$ \\
\hline & diAP8-diAP12 & $6.2(0.3)$ & $6.9(0.5)$ & $<5.5^{\mathrm{a}}$ & $>8.5^{\mathrm{a}}$ \\
\hline \multirow[t]{4}{*}{$\min$} & G8-G12 (wt) & $\sim 5.5(1.7)$ & $\sim 8.5(0.9)$ & $>8.5^{\mathrm{a}}$ & - \\
\hline & diAP8 & $\sim 6.2(1.4)$ & $\sim 8.0(0.8)$ & $6.1(0.3)$ & $7.7(0.3)$ \\
\hline & diAP12 & $\sim 6.0(1.5)$ & $\sim 8.0(0.9)$ & $5.7(0.4)$ & $8.5(0.3)$ \\
\hline & diAP8-diAP12 & $\sim 6.2(1.3)$ & $\sim 8.0(1.4)$ & $5.9(0.2)$ & $7.7(0.6)$ \\
\hline
\end{tabular}

The rate constants of folding and cleavage were fit by the equation: $k_{\mathrm{obs}}=k_{\max } /(1+$ $10^{\mathrm{pH}-\mathrm{pK}} \mathrm{a}_{1}+10^{\mathrm{pK}}{ }_{\mathrm{a} 2}-\mathrm{pH}+10^{\mathrm{pK}}{ }_{\mathrm{a} 2}-\mathrm{pK}_{\mathrm{a} 1}$ ), which yielded two apparent $\mathrm{pK}_{\mathrm{a}} \mathrm{s}$. For the $\mathrm{pH}$ dependence of cleavage of unmodified minimal and natural ribozyme, the $k_{\text {obs }}=k_{\max } /$ $\left(1+10^{\mathrm{pH}-\mathrm{pKa} 1}\right)$ equation was used and only one $\mathrm{pK}_{\mathrm{a}}$ was extracted.

${ }^{a}$ Fitting for some variants was only possible when $\mathrm{pK}_{\mathrm{a}}$ was constrained. For diAP8-U3 and A8-U3 the $\mathrm{pH}$ dependence of cleavage was best fit, when the second pKa was constrained to be $>8.5$. Furthermore, single diAP8 and diAP12 variants showed too small differences in cleavage between each $\mathrm{pH}$ studied (twofold) to obtain reliable fit and therefore the $\mathrm{pK}_{\mathrm{a}} \mathrm{s}$ were assigned to be $<5.5$ and $>8.5$. 
ribozyme folds with rates far exceeding the rate of cleavage. However, we cannot exclude binding of another $\mathrm{Mg}^{2+}$ ion to the active site without inducing conformational change, since our experimental approach does not measure the direct binding of ions, but rather the conformational consequences of this binding. Whether there is indeed a synergy between catalytic and structural $\mathrm{Mg}^{2+}$ and whether the $\mathrm{Mg}^{2+}$ with a 1 $\mathrm{mM}$ core folding affinity has a physiological and/or catalytic role remain to be determined and are currently being pursued.

The $\mathrm{Mg}^{2+}$ dependence of the steady-state relative fluorescence amplitudes of core and global folding are identical, even though each site requires a distinct concentration of $\mathrm{Mg}^{2+}$ to reach the maximum velocity of folding. The amplitude of the fluorescence variation depends on the degree to which the conformational change affects the environment of the fluorophore and provides equilibrium steady-state information about the population of molecules undergoing the transition upon addition of a ligand. Alternatively, the observed transient kinetic rate constants provide information about the mechanism of the folding events (Johnson 1992). The discrepancy between the amplitude and velocity of magnesium dependence of core folding suggests that the mechanisms of the core and global folding are different. Furthermore, it suggests that global folding in the presence of the auxiliary elements sets the population of molecules with the requisite energy to reach the transition state. Even though the separate folding events fit well to the Hill equation, the equation cannot rule out more complicated, multistate reactions, while combined. On one hand, Figure $2 \mathrm{~B}$ shows that the folding is a rather two-state event, although those particular events can be approximated as well as two sequential, more-or-less independent folding reactions. On another hand, the amplitude versus velocity comparison of pyC7 data in Figure 2D suggests that the folding is not approximated by a two-state reaction and there must be intermediate state(s). However, without more detailed temperature-dependent folding studies and core folding analysis in the background of a cleavable substrate, dissecting transient kinetic step of the active core falling back to the ground state conformation, we are unable to devise the simplest, most probably three-state model that could account for all of the data. The clear separation between global and core folding shows explicitly that the tertiary elements do not have a direct role in the core folding mechanism leading to the catalytic activity. Taken together, our results support the hypothesis that was previously introduced by Uhlenbeck's group, that tertiary interactions may have evolved to have kinetic values of global folding that adjust to the value needed for its physiological function (Nelson et al. 2005; Nelson and Uhlenbeck 2006, 2008). Our preliminary data on pyC folding, in the background of different tertiary arrangements in various natural hammerheads (IA Buskiewicz, unpubl.), suggest that global folding might become, under certain conditions, a limiting step for the core to undergo conformational change. As shown for the S. mansoni ribozyme in this study, the tertiary interaction only controls the population of core molecules with the requisite energy to reach the transition state. In conjunction with our current folding data, this supports the notion why the tertiary elements are not phylogenetically conserved (Flores et al. 2001) and can be replaced by other stabilizing tertiary elements (Saksmerprome et al. 2004). The rapid conformational switching between active and inactive states could be a critical property in the evolution of hammerheads and will defiantly help to understand the folding mechanism of the hammerheads with pseudoknot secondary motifs recently identified (Perreault et al. 2011).

The log-linear dependence of the cleavage rate on $\mathrm{pH}$ is generally accepted as evidence that the chemical step is rate-limiting in kinetically well-behaved hammerhead ribozyme sequences. However, at physiological $\mathrm{Mg}^{2+}$ concentrations, the log-linear $\mathrm{pH}$ profile levels off at high $\mathrm{pHs}$ (Canny et al. 2004), indicating that folding might become a rate-limiting step, as suggested by crystallographic analysis of cleavage in the crystal lattice (Murray et al. 2002). Indeed, our fluorescence folding analysis indicates that the $\mathrm{pH}$-dependent conformational change occurs locally in the core of the ribozyme and that this confined core change happens not only at high, but also at low pHs. Several models could explain the observed $\mathrm{pH}$ rate dependence of the folding. The simplest explanation is that the bell-shaped $\mathrm{pH}$ profile of folding could be interpreted by well-known acid and alkaline denaturation (Bevilacqua et al. 2005) of the G8-C3 Watson-Crick base pair, because replacement of either nucleotide of this base pair influences both the $\mathrm{pH}$ dependence of activity and core folding. This is the least speculative hypothesis, because it does not invoke protonation of any nucleobase. However, acidalkaline denaturation cannot explain why $\mathrm{pH}$ profiles of folding for G8-C3 and for diAP8-U3 or A8-U3 are different. In contrast to G8-C3, ribozymes with diAP8-U3 and $\mathrm{A} 8 \mathrm{-U} 3$ show no $\mathrm{pH}$ dependence in rate of folding between $\mathrm{pH} 5$ and 7. An alternative explanation of the $\mathrm{pH}$ dependence of folding would be the presence of an ionizable group at the same or different site within the ribozyme, responsible for weakening of the G8-C3 interaction at low or/ and high $\mathrm{pHs}$ and strengthening the ground-level interaction of either G8 or C3. In fact, the relative effect of different mutations at positions 8 and 3 was shown to depend on the identity of residue 17 in both the minimal and natural ribozymes (Nelson and Uhlenbeck 2008). This synergistic effect was explained by transient pairing between residues 17 and 3, which stabilize an inactive ground conformation. The cleavage site nucleotide (N17) is a relatively variable nucleotide in the core of the hammerhead ribozyme. It is commonly a $\mathrm{C}$ or an $\mathrm{A}$, bases that are frequently protonated at close to neutral pHs in various RNAs (Bevilacqua et al. 2005), seldom a U, and never a G (Flores et al. 2001; Carbonell et al. 2006). In the ground state, the $\mathrm{N} 6$ of $\mathrm{C} 17$ interacts with $\mathrm{N} 3$ of $\mathrm{C} 3$, 
forming a wobble-like base pair via a single hydrogen bond interaction (Supplemental Fig. S3A). In the active state, C17 interacts via $\mathrm{O} 2$ with $\mathrm{N} 6$ of A13. Interestingly, a site-specific $\mathrm{N} 3$ protonation of $\mathrm{C} 17$ or $\mathrm{C} 3$ could cause formation of a hydrogen bond to $\mathrm{O} 2$ of $\mathrm{C} 3$. This would transform the weak, one-hydrogen bond $\mathrm{C} 17-\mathrm{C} 3$ pair to a double bond $\mathrm{C}^{+} 17-\mathrm{C} 3$ or $\mathrm{C} 17-\mathrm{C}^{+} 3$ pair, which was shown to be thermodynamically equivalent to a G-U wobble base pair (SantaLucia et al. 1991; Masquida and Westhof 2000). The formation of C-C $\mathrm{C}^{+}$base pairs was previously shown in DNA (Gray et al. 1984; Edwards et al. 1990) and RNA (Brahms et al. 1967; Guschlbauer 1975). Interestingly, large changes in thermodynamic parameters were previously observed for loops holding $\mathrm{C}-\mathrm{C}$ interaction upon changing the $\mathrm{pH}$, because the $T_{\mathrm{m}}$ was increased by $12^{\circ} \mathrm{C}$, and $\Delta G$ becomes more favorable when the $\mathrm{pH}$ is lowered from pH 7.0 to 5.5 (SantaLucia et al. 1991). If protonation of $\mathrm{C} 17$ or $\mathrm{C} 3$ should occur in the ground state, then the active-state formation would be destabilized and could explain the observable decrease in the rate constant and amplitude of folding at low $\mathrm{pH}$ as shown in Figure 3. The possible protonation of the C17-C3 interaction could also explain the lack of $\mathrm{pH}$ dependence of folding for $\mathrm{U} 3$ variants. C17-U3 interaction in the ground state can form stable double-bond Watson-Crick like base pairs (Supplemental Fig. $\mathrm{S} 3 \mathrm{~B}$ ). If $\mathrm{C} 17$, protonated at $\mathrm{N} 3$, approached $\mathrm{U} 3$, no interaction could occur and the equilibrium would shift toward the active state (Supplemental Fig. S3B). In fact, all U3 mutants are stable at low $\mathrm{pH}$ in both folding and cleavage. Although the above proposed hypothesis of $\mathrm{C} 17-\mathrm{C} 3$ protonation explains the $\mathrm{pH}$ dependence of folding for the $\mathrm{U} 3$ variants at low $\mathrm{pHs}$, it cannot explain why the threehydrogen-bond base pair of diAP8-U3 does not fully restore the unmodified ribozyme activity. The diAP-U base pair has been previously shown to form a stable base pair in DNA and RNA duplexes (Howard et al. 1966; Muraoka et al. 1980; Howard and Miles 1984). As the terminal pair in an RNA duplex, diAP-U was shown to be $0.5 \mathrm{kcal} / \mathrm{mol}$ more stable than A-U, but $1.2 \mathrm{kcal} / \mathrm{mol}$ less stable than G-C, which also forms three hydrogen bonds. The lower stability of a diAP-U pair has been attributed to repulsive electrostatic interactions between the juxtaposed functional groups of the base pair. Taken together, this suggests that lower strength of the diAP-U base pair and possibly more favorable interaction of the U3 with $\mathrm{C} 17$ in the ground state would explain why with restoring the three-hydrogen-bond base pairs, we do not restore wild-type-like activity.

Introduction of the loop-loop interaction within the ribozyme was shown to induce a large semi-rigid bend that flexes the catalytic core in a defined direction (Martick and Scott 2006). Wobble-like mutants at the $8-3$ position in the minimal ribozyme (G8-U3 and diAP8-C3) reduce the catalytic rates by more than three orders of magnitude $(\mathrm{Fu}$ and McLaughlin 1992; Tuschl et al. 1993; Han and Burke 2005). In the native ribozyme, those mutations are less than one order of magnitude affecting both the folding and the activity. The wobble geometry of the 8-3 base pair would introduce only a $1 \AA$ displacement of the $2^{\prime}-\mathrm{OH}$ of G8, and the thermodynamic stability of the G8-U3 pair is only slightly weaker than that of a canonical G-C pair (Masquida and Westhof 2000), supporting the notions that the looploop interaction shifts the equilibrium of the core folding to the more locked conformation and small, otherwise deleterious distortions are not restricting this transition. The question whether the opening of the G8-C3 base pair leading to proton exchange is of a local fluctuation or occurs during a long-range distortion of the core, when an exchange of an N1-proton with the solvent is easily possible, will need to be further carefully studied. The greater-than-usual flexibility leading to the proton shuffle is right now only supported by formation of protonated wobble pairs: diAP8-C3 and A8-C3, with the same geometry as a G-U (Strobel et al. 1994; Sashital et al. 2004), which rescue the activity of the ribozyme in a way similar to that observed for G-C $\mathrm{C}^{+}$wobble in the Tetrahymena ribozyme (Knitt et al. 1994). To date, it is one of the few examples that demonstrate that, under certain circumstances, RNA tertiary structure can directly influence secondary structure (Knitt et al. 1994; Sashital et al. 2004).

A comparison of the cleavage and folding rates of the minimal and native double diAP8-diAP12 ribozyme variants showed that the $\mathrm{pH}$ dependence of cleavage activity is restricted in both of these ribozymes by different residues (Fig. $6 \mathrm{~A}-\mathrm{D})$. In the minimal ribozyme, the $\mathrm{pH}$-dependent cleavage activity of diAP8-diAP12 is comparable to rates of both cleavage and folding of the single diAP8 variant, whereas for the native ribozyme, the activity of the double diAP8-diAP12 ribozyme is analogous only to the rate of cleavage of a single diAP12 variant (Fig. 6C,D). Together, these results are consistent with a model in which the $\mathrm{pH}$-dependent cleavage of the double diAP8-diAP12 variant of the minimal ribozyme is folding-limited, whereas the $\mathrm{pH}$-dependent activity of the same variant in the background of the native ribozyme originates from the shift of the $\mathrm{pK}_{\mathrm{a}}$ of the $\mathrm{N} 1$ proton and/ or the exchange of the $\mathrm{O} 6$ carbonyl to the amino group of $\mathrm{G} 12$, the residue. The $\mathrm{pH}$-independent core folding of the minimal version of the $S$. mansoni ribozyme resembles rather global folding of the natural version, further supporting our above observation that the global folding, even much faster than the apparent rates of cleavage, is a limiting factor.

As presented here, combining time-resolved folding analysis with sequence and nucleotide analog variants provides a strategy to both establish relationships and to distinguish between kinetically equivalent mechanisms that commonly confound mechanistic analyses of acid-base catalysis in the ribozyme field. The number of similarities and differences between the two kinetic folding phases determined in the present study, particularly with regard to core folding, suggests that we are able to observe functionally significant changes in the environment of the core residues and that these changes are not part of, but only dependent on, global alteration of the hammerhead ribozyme-substrate complex. 
Our newly established site-specific folding assay will allow in the future, precise analysis of other site-specific mutations in the core of the hammerhead and other ribozymes, to answer questions of their role in the catalytic mechanism from both the chemical and folding point of view. The most intriguing question will be to answer the folding of G12 variants, which do not show $\mathrm{pH}$ dependence of cleavage or folding of newly identified ribozymes with pseudoknot motives.

\section{MATERIALS AND METHODS}

\section{Chemical synthesis}

All oligonucleotides were generated by solid-phase synthesis using nucleotide phosphoramidiates purchased from Glen Research or ChemGenes, and then deprotected and purified by denaturating polyacrylamide gel electrophoresis and HPLC, as described previously (Butcher and Burke 1994; Han and Burke 2005). Oligonucleotides containing pyrrolo-cytosine were synthesized in a similar way as described previously (Heckman et al. 2005), but deprotection was carried out under milder conditions (ammonium hydroxide for $12 \mathrm{~h}$ at room temperature instead of methylamine for $10 \mathrm{~min}$ at $60^{\circ} \mathrm{C}$ ).

\section{Ribozyme cleavage assays}

Catalytic activities of the hammerhead ribozyme and its variants were measured under single-turnover conditions as described previously (Han and Burke 2005). Cleavage reactions were carried out in $50 \mathrm{mM}$ MES ( $\mathrm{pH} 5-6)$, MOPS ( $\mathrm{pH}$ 6.5-7.5), HEPES ( $\mathrm{pH} 7.0$ 8.0), TRIS ( $\mathrm{pH} 7.5-8.5)$, TAPS ( $\mathrm{pH} 8.2-8.9$ ), and CHES ( $\mathrm{pH} 8.5-$ 9.0 ) buffers, containing additionally $100 \mathrm{mM} \mathrm{NaCl}$ and $10 \mathrm{mM}$ $\mathrm{MgCl}_{2}$. Complexes of ribozyme $(2 \mu \mathrm{M})$ and $5^{\prime}{ }^{32} \mathrm{P}$-end-labeled ribozyme substrate $(<5 \mathrm{nM})$ were prepared by heat denaturation for $5 \mathrm{~min}$ at $75^{\circ} \mathrm{C}$ and pre-incubated for $15 \mathrm{~min}$ at $25^{\circ} \mathrm{C}$ for equilibration and folding in the absence of $\mathrm{Mg}^{2+}$ and presence of $0.1 \mathrm{mM}$ EDTA. The cleavage reactions were initiated by adding $\mathrm{MgCl}_{2}$ solution to a final concentration of $10 \mathrm{mM}$ and performed at $25^{\circ} \mathrm{C}$. For slow kinetic reactions $(\mathrm{pH} 5.5-7.0) 2-\mu \mathrm{L}$ aliquots were removed at each time point and quenched with 10 volumes of loading solution ( $90 \%$ formamide, $50 \mathrm{mM}$ EDTA, $0.005 \%$ each of xylene cyanol and bromophenol blue) and immediately frozen. For fast kinetic reactions $(\mathrm{pH} 7.5-8.5)$, cleavage reactions were performed in a rapid quench flow apparatus (Kintek RQF-3). Reactions were initiated by rapidly mixing $(2 \mathrm{msec})$ equal volumes $(\sim 15 \mu \mathrm{L})$ of pre-assembled complexes with $\mathrm{Mg}^{2+}$ ions. Fast kinetic reactions were quenched with $90 \mu \mathrm{L}$ of the formamide-loading buffer and frozen immediately. Samples corresponding to each reaction time point were collected independently, electrophoresed on denaturating $20 \%$ polyacrylamide, $8 \mathrm{M}$ urea gel, and quantified using a Bio-Rad Molecular Imager FX system. The fraction cleaved $F_{t}$ at time $t$ was fit using GraphPad Prism 5 software either to a single-exponential equation at low and neutral $\mathrm{pH}(\mathrm{pH} 5.5-7.0)$ :

$$
F_{t}=F_{0}+\left(F_{\infty}-F_{0}\right)\left(1-\exp \left(-k_{o b s} t\right)\right)
$$

or to a biexponential equation at high $\mathrm{pH}(\mathrm{pH} 7.5-8.5)$, where the two cleavage rates were (the second observed rate was $\sim 2 \%$ of the total amplitude for $\mathrm{pH} 7.5$ and $6 \%-8 \%$ for $\mathrm{pH} 8.0-8.5$ )

$$
F_{t}=F_{0}+\left(F_{\infty}-F_{0}\right)\left(1-\alpha \exp \left(-k_{o b s, 1} t\right)-(1-\alpha) \exp \left(-k_{o b s, 2} t\right)\right)
$$

where $F_{0}$ is the zero-point correction, $F_{\infty}$ is the estimated plateau value at infinite time, $\alpha$ is the fraction of the cleaved population with a rate constant of $k_{\mathrm{obs}, 1}$, and $(1-\alpha)$ is the fraction cleaved with a rate constant of $k_{\mathrm{obs}, 2}$. Uncertainties were calculated from both curve fitting and from analysis of at least three-timesrepeated independent measurements for each variant studied. Furthermore, we tested three independent ribozyme and substrate preparations.

For $\mathrm{pH}$-dependent cleavage analysis, variants showing one titration group were fit to the Henderson-Hasselbalch equation:

$$
\mathrm{k}_{\mathrm{obs}}=\mathrm{k}_{\max } /\left(1+10^{\mathrm{pH}-\mathrm{pKa} 1}\right) .
$$

Variants displaying two titratable groups were fit with

$$
\mathrm{k}_{\mathrm{obs}}=\mathrm{k}_{\max } /\left(1+10^{\mathrm{pH}-\mathrm{pKa} 1}+10^{\mathrm{pKa} 2-\mathrm{pH}}+10^{\mathrm{pKa} 2-\mathrm{pKa} 1}\right) .
$$

For the very low and high $\mathrm{pH}$ conditions, the cleavage and folding assays were performed in smaller increments than displayed. (Instead of $0.5 \mathrm{pH}$ unit, 0.2 increments were tested, starting at $\mathrm{pH} 5$ and ending at $\mathrm{pH} 9$, respectively. The $\mathrm{pH} 9$ and 5 were not included in the fit.)

\section{Rapid folding kinetics}

Fluorescence stopped-flow measurements were performed on an SX-18MV spectrometer (Applied Photophysics). Hammerhead ribozymes and variants containing pyrrolo-cytosine at different positions were excited at $350 \mathrm{~nm}$ and measured after passing a KV500 cut-off filter (Schott). Hammerhead ribozyme-substrate (1-1.5 $\mu \mathrm{M})$ complexes with $\mathrm{C} 17$ on the substrate strand substituted with $2^{\prime}$-deoxycytosine were pre-equilibrated under the same conditions as described for cleavage. The folding reaction was initiated by rapid mixing (dead time $2 \mathrm{msec}$ ) of equal volumes $(47 \mu \mathrm{L})$ of each hammerhead ribozyme-substrate strand complex and $\mathrm{Mg}^{2+}$ (final concentration $10 \mathrm{mM}$ ) at $25^{\circ} \mathrm{C}$. Measurements of folding were performed in parallel in four different time ranges of 1000 data points each, and at least six shots were averaged per folding curve. Each folding experiment was performed at least three times with independently assembled ribozyme-substrate complexes. The reproducibility of the rate constant and amplitudes in the independent experiments was better than $\pm 5 \%$ and $\pm 10 \%$, respectively; within one experiment, the reproducibility from shot to shot was $\pm 2 \%$ for both parameters. The complex formation and stability were monitored by native gel electrophoresis at each $\mathrm{pH}$ (data not shown). The contribution of the $\mathrm{C} 17$ to $2^{\prime}$-deoxy-C17 substitution was checked at pHs from 5.5 to 7.0 , where cleavage is four orders of magnitude slower than folding, but no significant changes in folding were observed (data not shown). Folding data were fit using the single exponential function described above for cleavage analysis for moderate magnesium concentrations (up to $20 \mathrm{mM}$ ); at higher magnesium concentrations, two rates were observed, where the second rate did not exceed $5 \%$ of the total amplitude of fluorescence change. For the $\mathrm{pH}$-dependent analysis of the folding, only the first dominant rate was considered. The $\mathrm{pH}$ dependence of the folding was fit as above described for the $\mathrm{pH}$-dependent cleavage reactions with the Henderson-Hasselbalch equation. Plots of 
folding rate versus magnesium ion concentration were fit to a linear version of the Hill equation, representing a two-state model:

$$
k_{o b s}=\left(k_{\max } K_{\mathrm{d}}\left[\mathrm{Mg}^{2+}\right]^{\mathrm{n}}\right) /\left(1+K_{\mathrm{d}}\left[\mathrm{Mg}^{2+}\right]^{\mathrm{n}}\right)
$$

where $\left[\mathrm{Mg}^{2+}\right]$ is the magnesium ion concentration, $k_{\text {obs }}$ is the observed rate constant for the folding at a given magnesium concentration, $k_{\max }$ is $k_{\mathrm{obs}}$ at the saturating magnesium ions concentration, $n$ is the Hill constant representing the lower limit of the number of magnesium ions taken up by RNA, and $K_{\mathrm{d}}$ is the apparent dissociation constant for ion binding to RNA.

\section{SUPPLEMENTAL MATERIAL}

Supplemental material is available for this article.

\section{ACKNOWLEDGMENTS}

We thank Professor David Draper from Johns Hopkins University and Professor Dan Herschlag from Stanford University for insightful discussions. Furthermore, we thank Dr. Joyce Heckman from the University of Vermont for help with preparing this manuscript. This work was supported by the US National Institutes of Health, award no. AI044186.

Received October 19, 2011; accepted November 9, 2011.

\section{REFERENCES}

Bassi GS, Murchie AI, Walter F, Clegg RM, Lilley DM. 1997. Ioninduced folding of the hammerhead ribozyme: A fluorescence resonance energy transfer study. EMBO J 16: 7481-7489.

Berry DA, Jung K-Y, Wise DS, Sercel AD, Pearson WH, Mackie H, Randolph JB, Somers RL. 2004. Pyrrolo-dC and pyrrolo-C: Fluorescent analogs of cytidine and 2'-deoxycytidine for the study of oligonucleotides. Tetrahedron Lett 45: 2457-2461.

Bevilacqua PC, Brown TS, Chadalavada D, Lecomte J, Moody E, Nakano SI. 2005. Linkage between proton binding and folding in RNA: Implications for RNA catalysis. Biochem Soc Trans 33: 466-470.

Boots JL, Canny MD, Azimi E, Pardi A. 2008. Metal ion specificities for folding and cleavage activity in the Schistosoma hammerhead ribozyme. RNA 14: 2212-2222.

Brahms J, Maurizot JC, Michelson AM. 1967. Conformational stability of dinucleotides in solution. J Mol Biol 25: 481-495.

Brown D. 1971. Fused pyrimidines. Part II: Purines. Wiley, New York.

Butcher SE, Burke JM. 1994. Structure-mapping of the hairpin ribozyme. Magnesium-dependent folding and evidence for tertiary interactions within the ribozyme-substrate complex. J Mol Biol 244: 52-63.

Canny MD, Jucker FM, Kellogg E, Khvorova A, Jayasena SD, Pardi A. 2004. Fast cleavage kinetics of a natural hammerhead ribozyme. J Am Chem Soc 126: 10848-10849.

Carbonell A, De la Pena M, Flores R, Gago S. 2006. Effects of the trinucleotide preceding the self-cleavage site on eggplant latent viroid hammerheads: Differences in co- and post-transcriptional self-cleavage may explain the lack of trinucleotide AUC in most natural hammerheads. Nucleic Acids Res 34: 5613-5622.

Chartrand P, Harvey SC, Ferbeyre G, Usman N, Cedergren R. 1995. An oligodeoxyribonucleotide that supports catalytic activity in the hammerhead ribozyme domain. Nucleic Acids Res 23: 40924096 .
Chi YI, Martick M, Lares M, Kim R, Scott WG, Kim SH. 2008. Capturing hammerhead ribozyme structures in action by modulating general base catalysis. PLoS Biol 6: e234. doi: 10.1371/ journal.pbio.0060234.

Clouet-D'Orval B, Uhlenbeck OC. 1996. Kinetic characterization of two I/II format hammerhead ribozymes. RNA 2: 483-491.

Clouet-d'Orval B, Uhlenbeck OC. 1997. Hammerhead ribozymes with a faster cleavage rate. Biochemistry 36: 9087-9092.

Dash C, Rausch JW, Le Grice SF. 2004. Using pyrrolo-deoxycytosine to probe RNA/DNA hybrids containing the human immunodeficiency virus type-1 $3^{\prime}$ polypurine tract. Nucleic Acids Res 32: 1539-1547.

De la Pena M, Gago S, Flores R. 2003. Peripheral regions of natural hammerhead ribozymes greatly increase their self-cleavage activity. EMBO J 22: 5561-5570.

Doudna JA, Cormack BP, Szostak JW. 1989. RNA structure, not sequence, determines the $5^{\prime}$ splice-site specificity of a group I intron. Proc Natl Acad Sci 86: 7402-7406.

Edwards EL, Patrick MH, Ratliff RL, Gray DM. 1990. A.T and C.C+ base pairs can form simultaneously in a novel multistranded DNA complex. Biochemistry 29: 828-836.

Ferbeyre G, Smith JM, Cedergren R. 1998. Schistosome satellite DNA encodes active hammerhead ribozymes. Mol Cell Biol 18: 3880-3888.

Flores R, Hernandez C, de la Pena M, Vera A, Daros JA. 2001. Hammerhead ribozyme structure and function in plant RNA replication. Methods Enzymol 341: 540-552.

Forster AC, Symons RH. 1987. Self-cleavage of virusoid RNA is performed by the proposed 55-nucleotide active site. Cell 50: 9-16.

$\mathrm{Fu}$ DJ, McLaughlin LW. 1992. Importance of specific purine amino and hydroxyl groups for efficient cleavage by a hammerhead ribozyme. Proc Natl Acad Sci 89: 3985-3989.

Gray DM, Cui T, Ratliff RL. 1984. Circular dichroism measurements show that C.C+ base pairs can coexist with A.T base pairs between antiparallel strands of an oligodeoxynucleotide double-helix. Nucleic Acids Res 12: 7565-7580.

Guschlbauer W. 1975. Protonated polynucleotide structures. 16. Thermodynamics of the melting of the acid form of polycytidylic acid. Nucleic Acids Res 2: 353-360.

Hammann C, Lilley DM. 2002. Folding and activity of the hammerhead ribozyme. ChemBioChem 3: 690-700.

Hampel KJ, Burke JM. 2003. Solvent protection of the hammerhead ribozyme in the ground state: Evidence for a cation-assisted conformational change leading to catalysis. Biochemistry 42: 4421-4429.

Han J, Burke JM. 2005. Model for general acid-base catalysis by the hammerhead ribozyme: $\mathrm{pH}$-activity relationships of G8 and G12 variants at the putative active site. Biochemistry 44: 7864-7870.

Hardman SJ, Botchway SW, Thompson KC. 2008. Evidence for a nonbase stacking effect for the environment-sensitive fluorescent base pyrrolocytosine-comparison with 2-aminopurine. Photochem Photobiol 84: 1473-1479.

Heckman JE, Lambert D, Burke JM. 2005. Photocrosslinking detects a compact, active structure of the hammerhead ribozyme. Biochemistry 44: 4148-4156.

Hertel KJ, Pardi A, Uhlenbeck OC, Koizumi M, Ohtsuka E, Uesugi S, Cedergren R, Eckstein F, Gerlach WL, Hodgson R, et al. 1992. Numbering system for the hammerhead. Nucleic Acids Res 20: 3252.

Howard FB, Miles HT. 1984. 2NH2A X T helices in the ribo- and deoxypolynucleotide series. Structural and energetic consequences of 2NH2A substitution. Biochemistry 23: 6723-6732.

Howard FB, Frazier J, Singer MF, Miles HT. 1966. Helix formation between polyribonucleotides and purines, purine nucleosides and nucleotides. II. J Mol Biol 16: 415-439.

Johnson KA. 1992. The enzymes. In Transient state kinetic analysis of enzyme reaction pathways. pp. 1-61. Academic Press, San Diego.

Jorgensen WL, Pranata J. 1990. Importance of secondary interactions in triply hydrogen bonded complexes: Guanine cytosine vs uracil2,6-diaminopyridine. J Am Chem Soc 112: 2008-2010.

Kelley SO, Barton JK. 1999. Electron transfer between bases in double helical DNA. Science 283: 375-381. 
Khvorova A, Lescoute A, Westhof E, Jayasena SD. 2003. Sequence elements outside the hammerhead ribozyme catalytic core enable intracellular activity. Nat Struct Biol 10: 708-712.

Kim NK, Murali A, DeRose VJ. 2005. Separate metal requirements for loop interactions and catalysis in the extended hammerhead ribozyme. J Am Chem Soc 127: 14134-14135.

Knitt DS, Narlikar GJ, Herschlag D. 1994. Dissection of the role of the conserved G.U pair in group I RNA self-splicing. Biochemistry 33: 13864-13879.

Krakauer H. 1971. The binding of $\mathrm{Mg}^{++}$ions to polyadenylate, polyuridylate, and their complexes. Biopolymers 10: 2459-2490.

Kyogoku Y, Lord RC, Rich A. 1967. The effect of substituents on the hydrogen bonding of adenine and uracil derivatives. Proc Natl Acad Sci 57: 250-257.

Lambert D, Heckman JE, Burke JM. 2006. Three conserved guanosines approach the reaction site in native and minimal hammerhead ribozymes. Biochemistry 45: 7140-7147.

Lee TS, Silva Lopez C, Giambasu GM, Martick M, Scott WG, York DM. 2008. Role of $\mathrm{Mg}^{2+}$ in hammerhead ribozyme catalysis from molecular simulation. J Am Chem Soc 130: 3053-3064.

Martick M, Scott WG. 2006. Tertiary contacts distant from the active site prime a ribozyme for catalysis. Cell 126: 309-320.

Martick M, Lee TS, York DM, Scott WG. 2008. Solvent structure and hammerhead ribozyme catalysis. Chem Biol 15: 332-342.

Masquida B, Westhof E. 2000. On the wobble GoU and related pairs. RNA 6: 9-15.

McDowell SE, Jun JM, Walter NG. 2010. Long-range tertiary interactions in single hammerhead ribozymes bias motional sampling toward catalytically active conformations. RNA 16: 2414-2426.

Muraoka M, Miles HT, Howard FB. 1980. Copolymers of adenylic and 2-aminoadenylic acids. Effect of progressive changes in hydrogen bonding and stacking on interaction with poly(uridylic acid). Biochemistry 19: 2429-2439.

Murray JB, Dunham CM, Scott WG. 2002. A pH-dependent conformational change, rather than the chemical step, appears to be ratelimiting in the hammerhead ribozyme cleavage reaction. J Mol Biol 315: 121-130.

Nelson JA, Uhlenbeck OC. 2006. When to believe what you see. Mol Cell 23: $447-450$.

Nelson JA, Uhlenbeck OC. 2008. Minimal and extended hammerheads utilize a similar dynamic reaction mechanism for catalysis. RNA 14: 43-54.

Nelson JA, Shepotinovskaya I, Uhlenbeck OC. 2005. Hammerheads derived from sTRSV show enhanced cleavage and ligation rate constants. Biochemistry 44: 14577-14585.

Penedo JC, Wilson TJ, Jayasena SD, Khvorova A, Lilley DM. 2004. Folding of the natural hammerhead ribozyme is enhanced by interaction of auxiliary elements. RNA 10: 880-888.

Perreault J, Weinberg Z, Roth A, Popescu O, Chartrand P, Ferbeyre G, Breaker RR. 2011. Identification of hammerhead ribozymes in all domains of life reveals novel structural variations. PLoS Comput Biol 7: e1002031. doi: 10.1371/journal.pcbi.1002031.
Prody GA, Bakos JT, Buzayan JM, Schneider IR, Breuning G. 1986. Autolytic processing of dimeric plant virus satellite RNA. Science 231: $1577-1580$.

Przybilski R, Hammann C. 2007a. Idiosyncratic cleavage and ligation activity of individual hammerhead ribozymes and core sequence variants thereof. Biol Chem 388: 737-741.

Przybilski R, Hammann C. 2007b. The tolerance to exchanges of the Watson-Crick base pair in the hammerhead ribozyme core is determined by surrounding elements. RNA 13: 1625-1630.

Roychowdhury-Saha M, Burke DH. 2006. Extraordinary rates of transition metal ion-mediated ribozyme catalysis. RNA 12: $1846-1852$

Rueda D, Wick K, McDowell SE, Walter NG. 2003. Diffusely bound $\mathrm{Mg}^{2+}$ ions slightly reorient stems I and II of the hammerhead ribozyme to increase the probability of formation of the catalytic core. Biochemistry 42: 9924-9936.

Ruffner DE, Stormo GD, Uhlenbeck OC. 1990. Sequence requirements of the hammerhead RNA self-cleavage reaction. Biochemistry 29: 10695-10702.

Saksmerprome V, Roychowdhury-Saha M, Jayasena S, Khvorova A, Burke DH. 2004. Artificial tertiary motifs stabilize trans-cleaving hammerhead ribozymes under conditions of submillimolar divalent ions and high temperatures. RNA 10: 1916-1924.

Sander C, Ts'o PO. 1971. Interaction of nucleic acids. 8. Binding of magnesium ions by nucleic acids. J Mol Biol 55: 1-21.

SantaLucia J Jr, Kierzek R, Turner DH. 1991. Stabilities of consecutive A.C, C.C, G.G, U.C, and U.U mismatches in RNA internal loops: Evidence for stable hydrogen-bonded U.U and C.C+ pairs. Biochemistry 30: 8242-8251.

Sashital DG, Cornilescu G, McManus CJ, Brow DA, Butcher SE. 2004. U2-U6 RNA folding reveals a group II intron-like domain and a four-helix junction. Nat Struct Mol Biol 11: 1237-1242.

Scott WG, Murray JB, Arnold JR, Stoddard BL, Klug A. 1996. Capturing the structure of a catalytic RNA intermediate: The hammerhead ribozyme. Science 274: 2065-2069.

Strobel SA, Cech TR, Usman N, Beigelman L. 1994. The 2,6diaminopurine riboside-5-methylisocytidine wobble base pair: An isoenergetic substitution for the study of G.U pairs in RNA. Biochemistry 33: 13824-13835.

Thompson KC, Miyake N. 2005. Properties of a new fluorescent cytosine analogue, pyrrolocytosine. J Phys Chem B 109: 6012-6019.

Tinsley RA, Walter NG. 2006. Pyrrolo-C as a fluorescent probe for monitoring RNA secondary structure formation. RNA 12: 522-529.

Tuschl T, Ng MM, Pieken W, Benseler F, Eckstein F. 1993. Importance of exocyclic base functional groups of central core guanosines for hammerhead ribozyme activity. Biochemistry 32: 11658-11668.

Walter NG, Burke JM. 1997. Real-time monitoring of hairpin ribozyme kinetics through base-specific quenching of fluorescein-labeled substrates. RNA 3: 392-404.

Zhang X, Wadkins RM. 2009. DNA hairpins containing the cytidine analog pyrrolo-dC: Structural, thermodynamic, and spectroscopic studies. Biophys J 96: 1884-1891. 

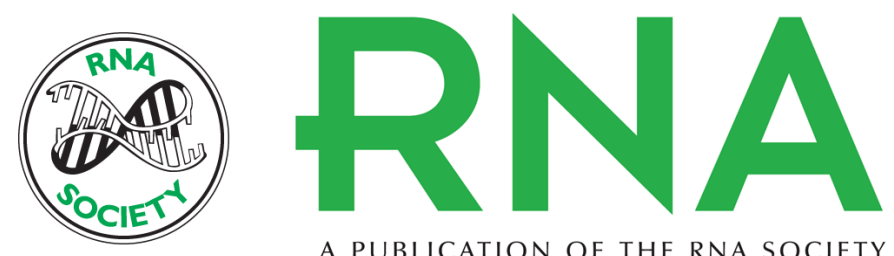

A PUBLICATION OF THE RNA SOCIETY

\section{Folding of the hammerhead ribozyme: Pyrrolo-cytosine fluorescence separates core folding from global folding and reveals a $\mathrm{pH}$-dependent conformational change}

Iwona A. Buskiewicz and John M. Burke

RNA 2012 18: 434-448 originally published online January 24, 2012

Access the most recent version at doi:10.1261/rna.030999.111

Supplemental Material

References

License

Email Alerting Service
http://rnajournal.cshlp.org/content/suppl/2011/12/27/rna.030999.111.DC1

This article cites 67 articles, 20 of which can be accessed free at: http://rnajournal.cshlp.org/content/18/3/434.full.html\#ref-list-1

Receive free email alerts when new articles cite this article - sign up in the box at the top right corner of the article or click here. 